\title{
Experimental Study on Influence of Connection Defects on Joint Strength of Half-Grouted Sleeve Splicing of Rebar
}

\author{
Hong Guo $\mathbb{D}^{1},{ }^{1}$ Jiaxin Zhang, ${ }^{1}$ and Changwei Wang ${ }^{2}$ \\ ${ }^{1}$ Civil Engineering, North University of China, Taiyuan, Shanxi, China \\ ${ }^{2}$ China Shanxi Sijian Group Co., Ltd., Taiyuan, Shanxi, China \\ Correspondence should be addressed to Hong Guo; guohongh@nuc.edu.cn
}

Received 5 October 2019; Revised 14 May 2020; Accepted 26 May 2020; Published 13 June 2020

Academic Editor: José Aguiar

Copyright (c) 2020 Hong Guo et al. This is an open access article distributed under the Creative Commons Attribution License, which permits unrestricted use, distribution, and reproduction in any medium, provided the original work is properly cited.

The different types of defects of half grouting sleeves will remarkably increase the risks of precast concrete structures. In order to better understand the defects of rebar connections between half grouting sleeves, six different test groups on insufficient grout height, insufficient compactness, rebar offset, insufficient rebar anchor length, overtime grouting, and control group had been researched. The uniaxial tension experiments were conducted for the 24 different specimens, and load-slip curves were also analyzed. The results of the experiments showed that the outside of the rebar was snapped off as for the destruction mode, while the destruction mode changed as the increment of the degree of defect surpasses the critical value. The bearing capacity and deformability were dropped with the increase in the degree of defects, and a critical value of rebar anchoring length of sleeve was discovered. In the end, different finite-element models were built based on different deficient situations, and load-slip constitutive model was obtained, which would be helpful to evaluate the structural performance of precast concrete structures in construction.

\section{Introduction}

Precast concrete (PC) structure is widely adopted because of its notable advantages such as high quality, high industrialization level, high construction speed, low labor intensity, and green construction [1]. At present, the factors that influence the assembled building construction safety mainly include node and structure designs. Grouted sleeve effectively solves the technical problems of node connection to precast the concrete component. Grouted sleeve, including whole-grouted sleeve and half-grouted sleeve [2], among which the rebar of one end of half-grouted sleeve was processed into external straight thread connected to straight thread in sleeve and the other end was inserted into sleeve cavity, was connected by injecting special joint grouting material, and this process is more widely and conveniently adopted.

Scholars at home and abroad have developed a series of researches about the prefabricated concrete structures. Qin et al. [3] had compared the seismic resistance of monolithic precast concrete structure (MPCS) with cast-in-place structure (CIPS). The results show that, except for typical features, MPCS and CIPS generally have similar seismic responses and prove that they have better seismic performance without collapse under high-intensity seismic waves. Zhang et al. [4] studied and predicted the service life of precast concrete structures in chloride environment. The analysis shows that the initial state of corrosion and use limit state are sensible of the chloride diffusion coefficient within connecting area, and a higher pitting factor has obvious influence on the bearing capacities of PC structures. Wu $t$ al. [5] presented the calculation method of the bending resisted bearing capacity of precast grouted shear wall influenced by node displacements. Pan et al. [6] strengthened the precast reinforced frame to reduce the possibility of continuous collapse by externally stuck carbon fibre-reinforced polymer (CFRP) sheets to hybrid fibre-reinforced polymer (HERP) anchors. The reinforce result is extremely evident at the early stage of catenary effect, and there is no shearing failure of HERP anchors, which prove the effectiveness of the anchoring method. Guo et al. [1] raised a simplified calculation method to predict the lateral strength of the precast shear 
wall. Taking a three-decker precast wallboard structure as an example, they used a proposed numerical model to evaluate the collapse performance of raised precast structural system, and the results show that the structural system with bolt connections has higher stiffness and seismic resistance against collapse.

The above content is the research of some scholars on the precast structure, so it can be seen that the precast structure is very advanced compared with the traditional structure. However, the most important factor affecting the prefabricated structure is the connection of the half-grouted sleeve. So the connection performance of the half-grouted sleeve is very important. The following is the research of some scholars on the half-grouted sleeve. The grouted sleeve invented by Dr. Yu Zhanshu in 1967 was firstly applied to build the 39-tier hotels in the 1970s, and it has been used for 52 years. The America Concrete Association included the rebar sleeve connection technology as one of the main techniques of rebar connection. Zhang et al. [7] studied the mechanical properties of half-grouted sleeve at high temperature. The stretch results from 12 half-grouted sleeve specimens and 12 rebars at different temperatures showed that the tensile properties of half-grouted sleeve joints are directly influenced by temperatures. Zhao et al. [8] studied a kind of glass fibre reinforced polymer splicing sleeve with corrugation (CP-GFRP) which has advantages such as light weight, sheet material, and excellent tensile properties. $\mathrm{Xu}$ et al. [9] studied 126 specimens with insufficient grouting structure in total. Regarding the destruction models under different defect levels, a bond stress-slip constitutive model has been proposed and it was beneficial to evaluate the structural performance of PC structures in practice. Lamport et al. [10] studied the influences of the relative position of loading pattern, shear connection, and the connection adhesive strength from grouting strength to grouting pile casing. The experiment results show that the ultimate bearing capacity of sleeve connection is related to the square root of the grouting strength. Hayashi et al. [10] tested the bond stress distribution of the deformed bar embedded in the grouting sleeve, and the relations between the maximum local bounding stress and rebar slip were given. Einea et al. [11] proposed four types of grouting sleeve structures with different internal parts; bond strength was obtained theoretically considering the restraining action of sleeve, and the results were compared with the result of the grout joints' drawing experiment. The finite element simulation of new pore-forming grouted connector with welded closure confinement steels (NPGCS) spaced model studied by Wu and Liang et al. [12] is reliable and relatively accurate.

The following researches were mainly processed based on grouting sleeve connection; however, during the assembled building construction, conditions such as insufficient anchoring length, rebar position offset, and grouting defects caused by grout blocked, leaking, and temperature usually occurred. Therefore, 24 half-grouted sleeve connection joints were made in this experiment in order to stimulate the five defects including vertical insufficient grouting height, insufficient compactness, rebar offset, insufficient rebar anchor length, and overtime grouting that were produced in the practical construction process. Uniaxial tension experiment was made to analyze the influences on the defects above the connection performance of halfgrouted sleeve joints.

\section{Experimental Program}

2.1. Materials and Specimen Preparation. This experiment used the nodular cast iron grouting sleeve (see Figure 1); one end is the mechanical one of ribbed rolled straight thread, and the other one is a sleeve cavity that was used to insert rebar and pour into grouting material. It suited the HRB400 [13] rebar with $16 \mathrm{~mm}$ in diameter, the anchor length is $130 \mathrm{~mm}$, the yield strength and the ultimate strength that connected the rebars are $400 \mathrm{MPa}$ and $540 \mathrm{MPa}$, and the results from the experiment show that the average yield strength and ultimate strength are $416 \mathrm{MPa}$ and $582 \mathrm{MPa}$ (see Table 1). The exclusive grouting material with $85 \mathrm{MPa}$ [15] compressive strength was used as the bonding material, and the average compressive resistance is $86.5 \mathrm{MPa}$ (see Table 2).

(1) Control group: we made the control group according to the design of GTZB4 16/16C half-grouted sleeve, the lower part is the HRB400 [13] rebar with $16 \mathrm{~mm}$ in diameter that was inserted for $130 \mathrm{~mm}$, the grouting material was fully mixed according to $12 \%$ of the hydration ratio, and it also avoids the bubbles from it; then, after 2-minute stand, we used the grouting spear manually grouting through inlet, and we also used the rubber plug to block off the outlet after the grouting material was evenly bubbled out of it.

(2) Insufficient grout height specimen: leaking might happen if the rubber plugs blocked off the sleeve loosely, and it will cause the top of the sleeve connection failure; therefore, a group of grouting defects with a height of $104 \mathrm{~mm}(6.5 \mathrm{~d})$ was made.

(3) Insufficient compactness specimen: insufficient compactness specimen, i.e., the defect caused by bubbles from the grouting material. We evenly mixed the grouting material with EPS foam particles of $1-2 \mathrm{~mm}$ in diameter and stimulated the grouting defect produced in the process of hydration, and we also made a group of specimens with $20 \%$ of porosity.

(4) Rebar offset specimen: engineering construction quality defects often lead to position shift of rebar or sleeve and forms rebar offset joints; machine connection end is inserted into the center of sleeve, while the other end of offset rebar crosses rib contacting the sleeve wall, and the rebar axis Max excursion is $5 \mathrm{~mm}(0.3 \mathrm{~d})$. As a result, we made a group of offset joint specimens.

(5) Insufficient rebar anchor length specimen: insufficient rebar retention length will cause insufficient rebar anchor length, which is a relatively serious engineering weakness. For this reason, 3 groups of 

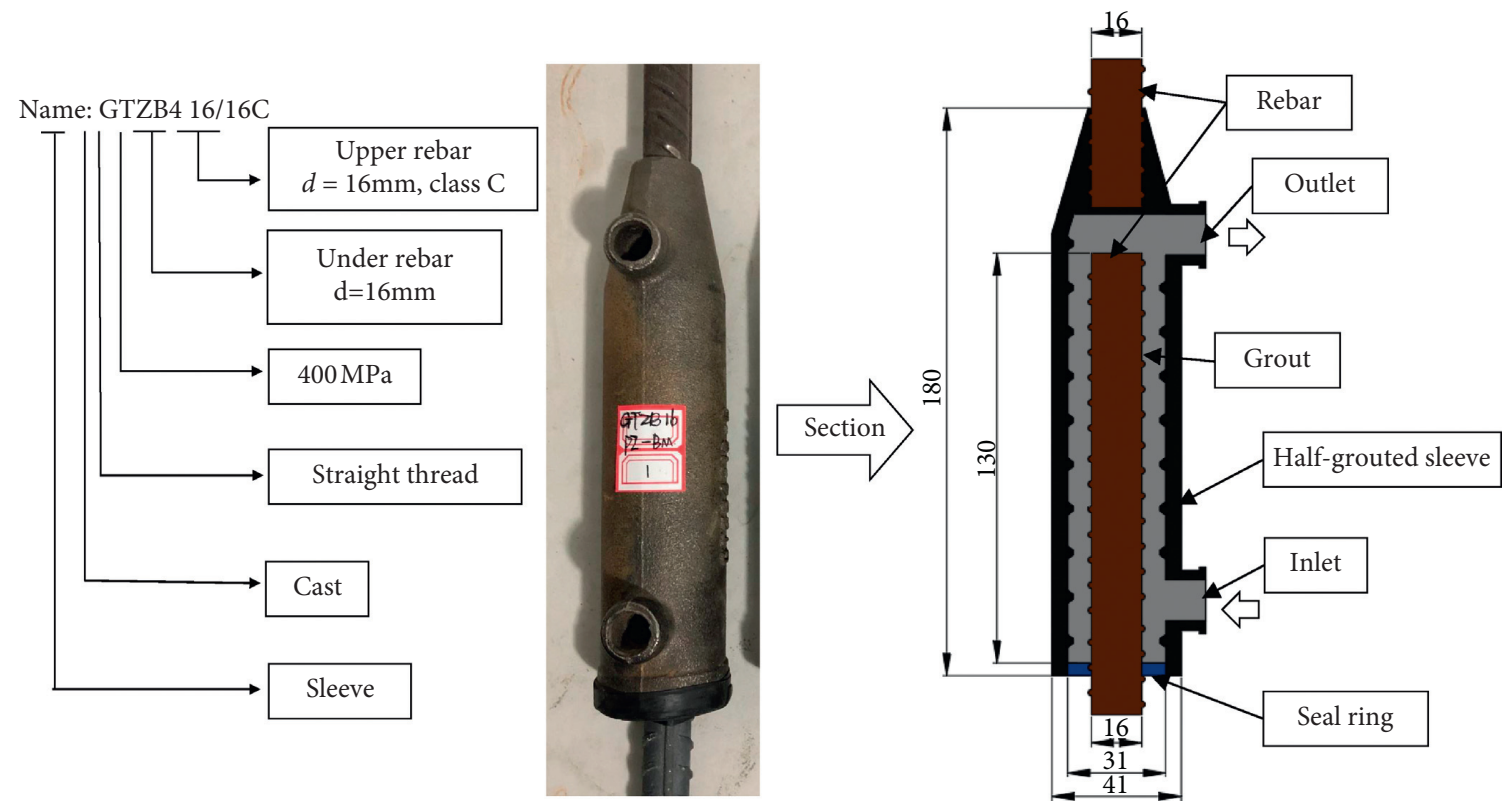

Figure 1: Simplified diagram of half-grouted sleeve (unit: $\mathrm{mm}$ ).

TABLE 1: HRB400 rebar base material testing data.

\begin{tabular}{lccccc}
\hline Number & 1 & 2 & 3 & AVG & Standard* \\
\hline Rebar diameter $(\mathrm{mm})$ & 16 & 16 & 16 & 16 & - \\
Yield strength $(\mathrm{MPa})$ & 413 & 413 & 421 & 416 & $\geq 400$ \\
Tensile strength $(\mathrm{MPa})$ & 580 & 584 & 583 & 582 & $\geq 540$ \\
\hline
\end{tabular}

* The standard means the demand of rebars according to the specification content of GB50010 [14].

TABLE 2: 28-day compressive strength measured value of grouting material (unit: $\mathrm{MPa}$ ).

\begin{tabular}{lcccccccc}
\hline $\begin{array}{l}\text { Hydration } \\
\text { ratio (\%) }\end{array}$ & 1 & 2 & 3 & 4 & 5 & 6 & AVG & Standard* \\
\hline 12 & 86.1 & 89.4 & 85.8 & 83.1 & 87.4 & 87.5 & 86.5 & $\geq 85$ \\
\hline
\end{tabular}

*The standard means the demand of grout according to the specification content of JGT 408 [15].

specimens with different anchoring depths were made, and the inserted rebar depths were $120 \mathrm{~mm}$ (7.5 d), $104 \mathrm{~mm}(6.5 \mathrm{~d})$, and $88 \mathrm{~mm}$ (5.5 d).

(6) Overtime grouting specimen: we mixed excessive grouting material at one time, the mixed grouting material was placed for too long, and it influences the liquidity and the expansion rate performance. We stimulated the grouting specimen after grouting timeout, fully mixed the grouting material according to instructions, and stood for $30 \mathrm{~min}$; then, we mixed it again and grouted. Therefore, one group of overtime grouting specimens was made.

Six types of specimens (see Figure 2) including 1 control group, 1 group of insufficient grout height, 1 group of insufficient compactness, 1 group of rebar offset, 3 groups of insufficient rebar anchor length, and 1 group of overtime grouting were made. 3 control individuals were prepared for the same type of specimens; as a result, 24 specimens were made in the experiment.

2.2. Experimental Procedures. In order to test the load-slip curves of the specimens, a WED-1000 electronic universal machine was used to vertically fix two ends of the sleeve joints, gradually loading from zero until the specimen destroyed, and the separate speed of universal machine chuck is $0.5 \mathrm{kN} / \mathrm{s}$. Independent grouting method of vertical members was applied, uniaxial tension experiment was made after 28 days of specimen maintenance, and the experimental procedure is shown in Figure 3. The applied tensile load was measured by the inbuilt load cell, and the slip of reinforcing rebar to sleeve was monitored by linear variable differential transformer (LVDT). The experimental conditions are shown in Table 3.

\section{Finite Element Analysis}

Currently, China's detection technology of the grouting sleeve is not mature, so it is necessary to analyze and study the force performance of the grouting sleeve in various circumstances through finite element values and further research the failure mechanism of the grouting sleeve except relevant experiments. Applying finite element software to stimulate data analysis of half-grouted sleeve joints, we compared the load-slip curves to demonstrate the reliability of the experiment and stimulation and analyzed the internal force of grouting sleeve joints.

As there is no mature constitutive model of the grouting material, the constitutive model of the concrete was applied to build the constitutive model of the grouting material in the finite element analysis. The bonding material was the BY (S)YJ85 grouting material, the compressive strength was $86.5 \mathrm{MPa}$, the density was $2500 \mathrm{~kg} / \mathrm{m}^{3}$, the elastic modulus was $38 \mathrm{GPa}$, Poisson's ratio was 0.2 , and the bilinear model [16] was applied to obtain the grouting stress-strain curve (see Figure 4). 


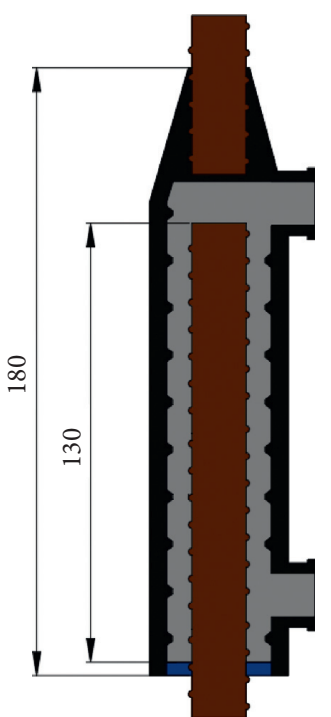

(a)

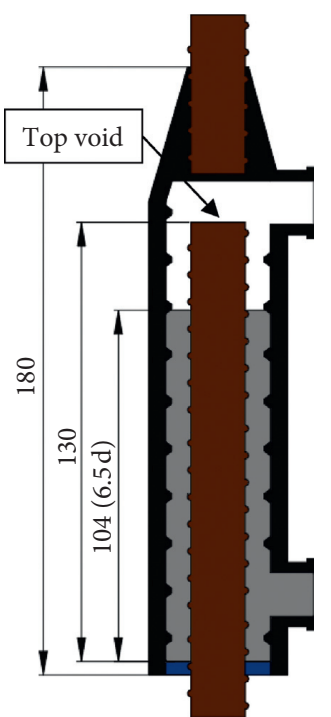

(b)

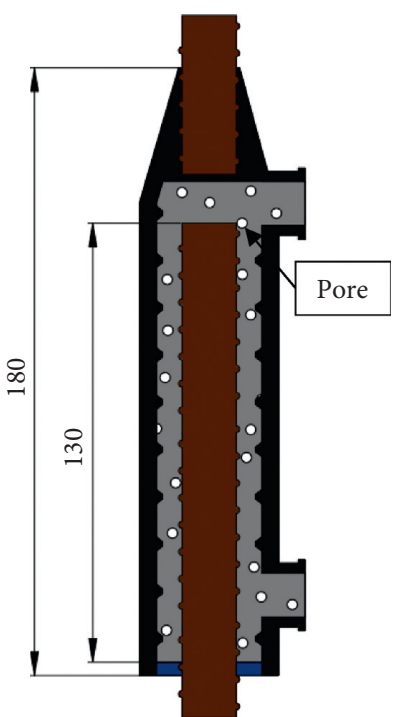

(c)

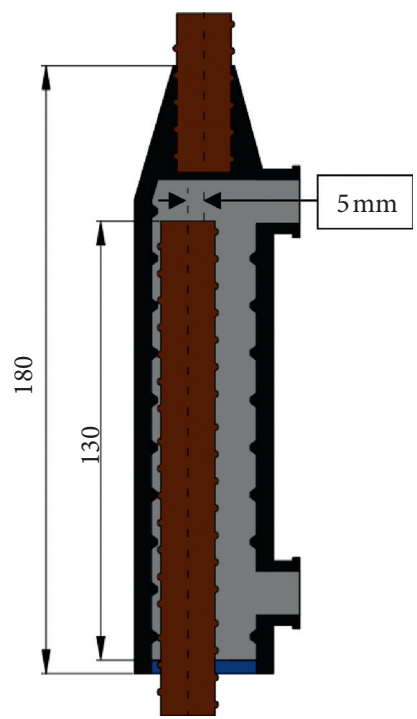

(d)
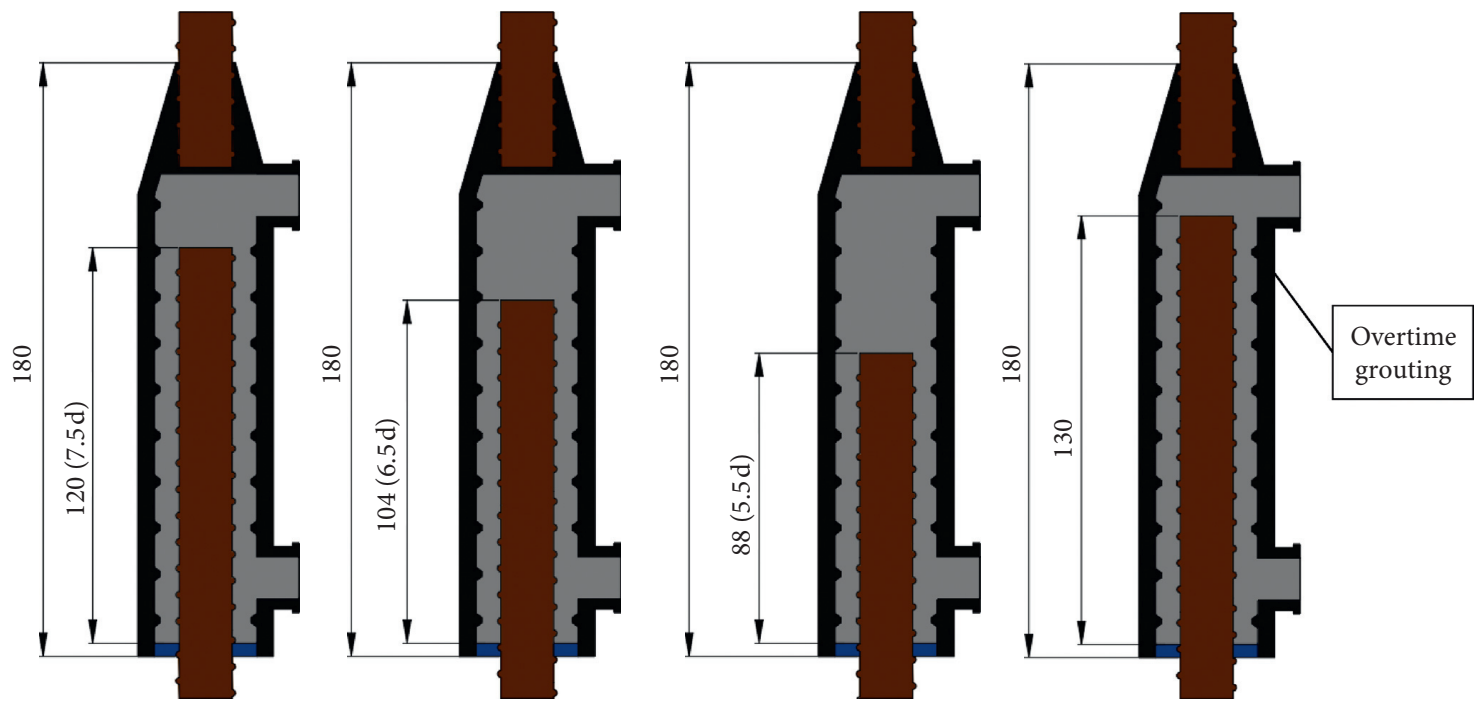

(f)

FIGURE 2: Detailed specimen design sample: (a) control group; (b) insufficient grout height specimen; (c) insufficient compactness specimen; (d) rebar offset specimen; (e) insufficient rebar anchor length specimen; (f) overtime grouting specimen (unit: $\mathrm{mm}$ ).

The density of the half-grouted sleeve was $7300 \mathrm{~kg} / \mathrm{m}^{3}$, the elastic modulus was $205 \mathrm{GPa}$, Poisson's ratio was 0.3 , the ultimate strength was $550 \mathrm{MPa}$, and the sleeve stress-strain curve was conducted according to the elastic model (see Figure 5). The HRB400 [13] deformed bars of $16 \mathrm{~mm}$ in diameter were applied in the experiment; the average yield strength and the ultimate strength were $416 \mathrm{MPa}$ and $582 \mathrm{MPa}$; Young's modulus was $210 \mathrm{MPa}$, Poisson's ratio was 0.3 , the elastic modulus was $203 \mathrm{MPa}$, and the density was $7850 \mathrm{~kg} / \mathrm{m}^{3}$. As for the rebar stress-strain curve, you can refer to it (see Figure 6) from Figure 3.3-1(b) of the references [17].

\section{Experiment Results and Analyses}

When load is less, the rebar and the sleeve are all in the elastic stage and there is no slip happening to them during the experiment. As the load grows, different developments happen in specimens with distinct defects. For the specimens with less defects, a larger slip occurred between rebars and sleeves, and the destruction mode is rebar broken. As the defects grow, the slips decrease, the bonding strength between the grouting material and the sleeve constantly reduces, and this eventually leads to rebar pullout failure. The experiment shows that the specimens displayed three destruction modes [18], i.e., rebar tension fracture, rebar pull out due to bond failure, and the thread shear failure.

The compressive resistance of grout sleeve splicing rebar joints should not be less than the standard value of tensile strength of connecting bars (the standard value of tensile strength of rebars in this research was $540 \mathrm{MPa}$ ), and it should break outside the joint when destruction happens. The yield strength of the grout sleeve splicing rebar joints 

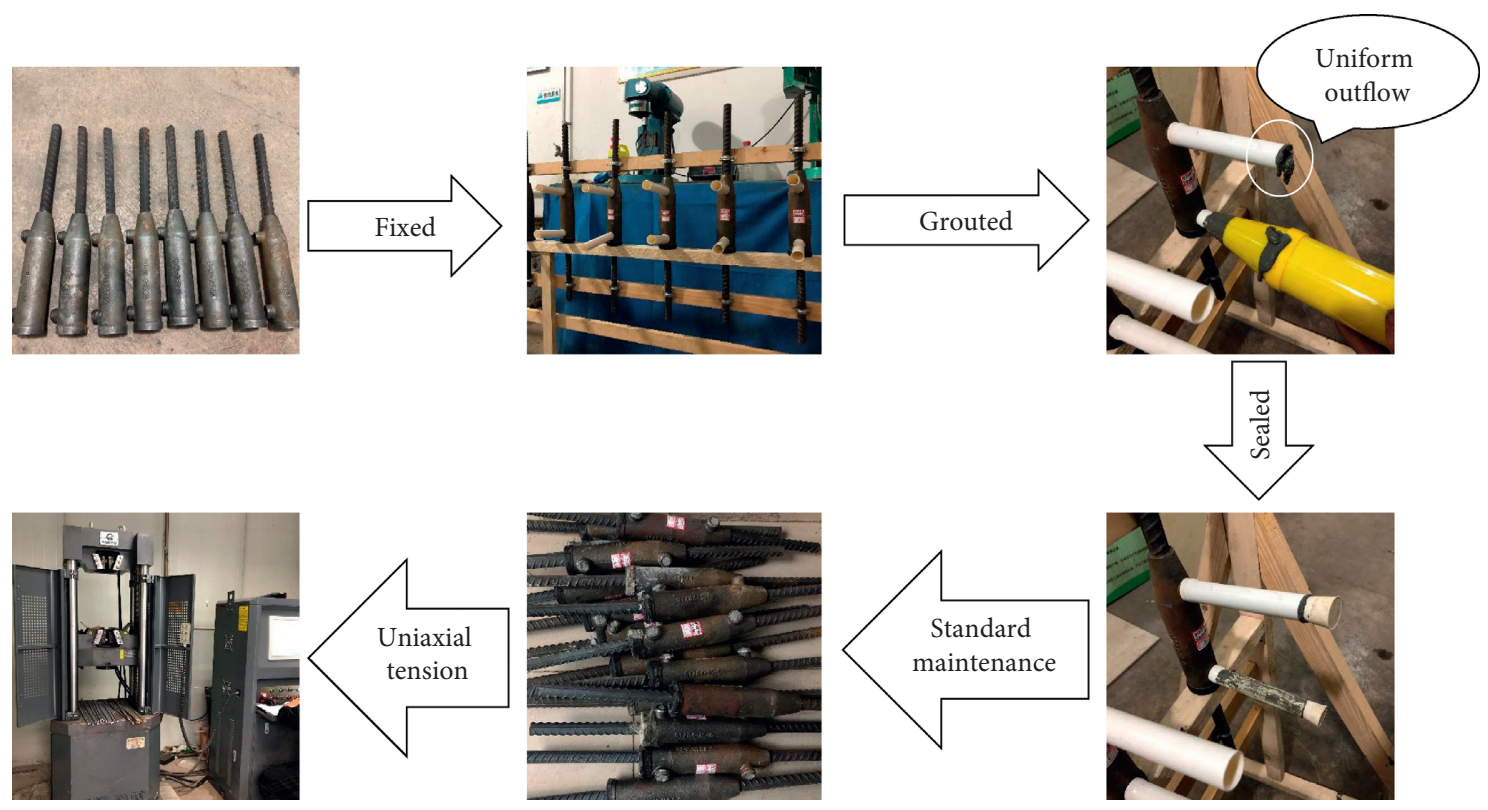

FIGURE 3: Experimental flowchart.

TABLE 3: Experimental conditions.

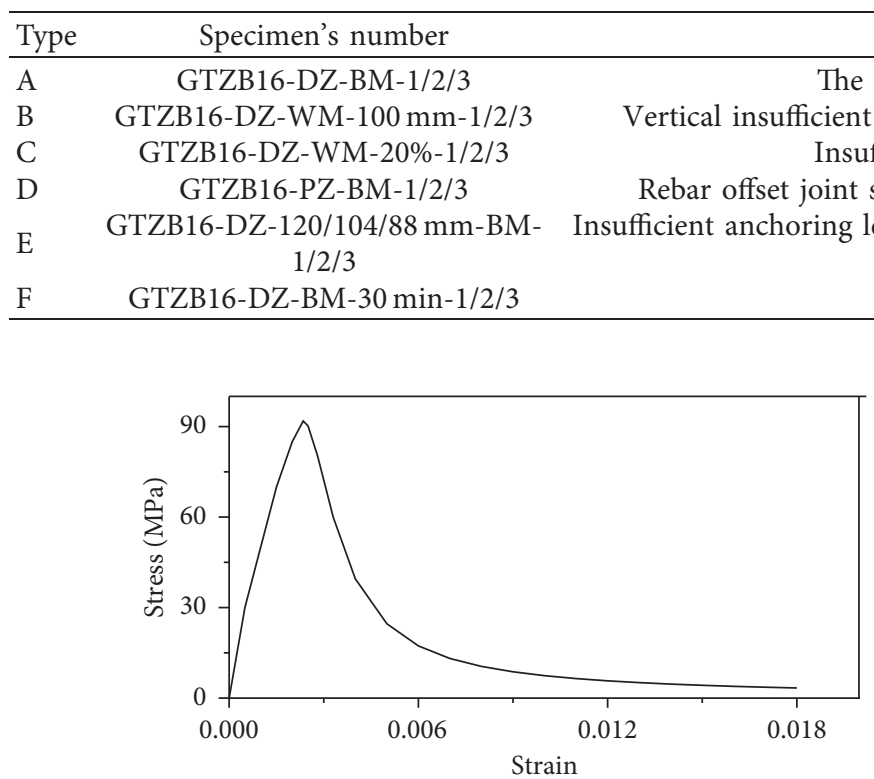

(a)

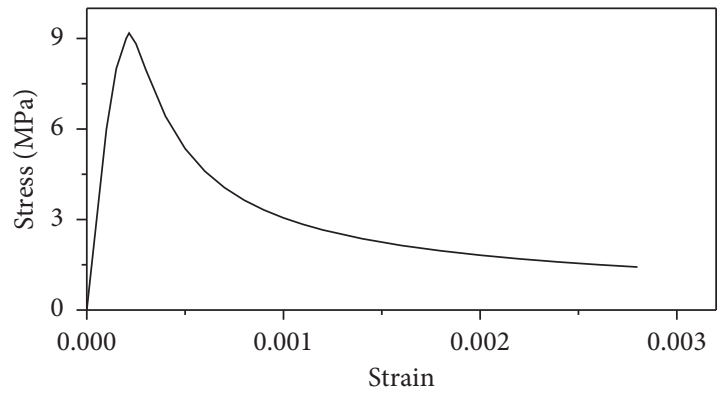

(b)

FIgURE 4: Stress-strain curve of grout: (a) uniaxial compression of concrete; (b) uniaxial tension of concrete.

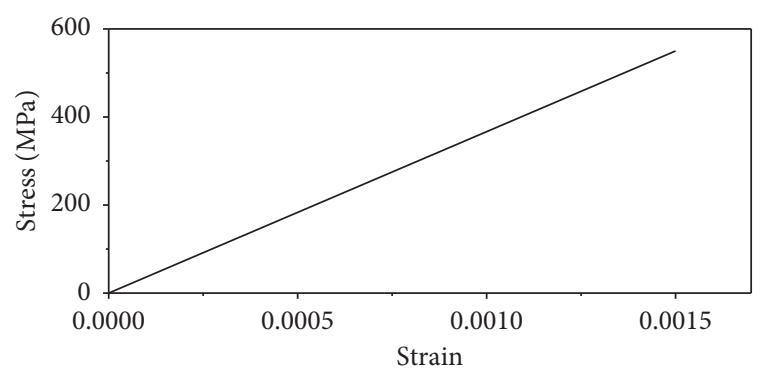

Figure 5: Sleeve stress-strain curve.

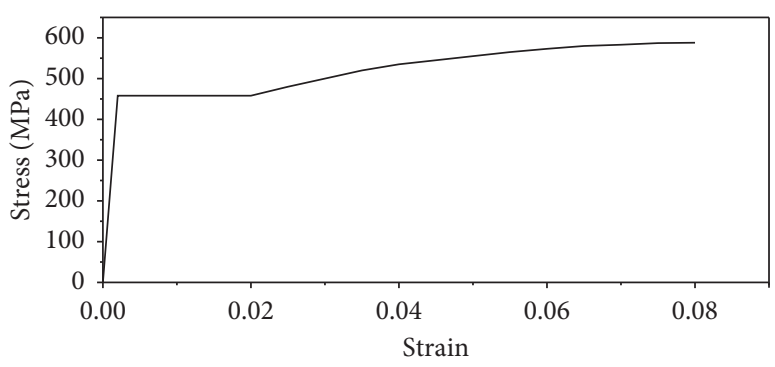

FIgURE 6: Rebar stress-strain curve. 
should not be less than the standard value of yield strength connecting the rebars (the rebar yield strength standard value in this research was $400 \mathrm{MPa}$ ). The specimens were qualified when simultaneously meeting the two demands above.

4.1. Control Group. The load-slip curves of the control group are shown in Figure 7. Experimental results of 3 control groups are extremely close; therefore, we take average value $(A V G)$ as the reference group. The curve changes evidently resulting in four stages after the instrument applied a tensile load evenly. At the first stage (stage $A B$ ), the load linearly increases as the slip grows, and the specimen is in elastic deformation; the second stage (stage $\mathrm{BC}$ ) is the horizontal yield stage, and the average yield load is $87.35 \mathrm{kN}$; at the third stage (stage CD), because of the high anchoring capacity of the grouting material, the load exerted on gradually rises, and it leads to the strengthening stage. Point $D$ represents the ultimate load, $120.66 \mathrm{kN}$ Max; at the fourth stage (stage $\mathrm{DE}$ ), the necking of rebars occurs, the curve fast drops, the average slip is $7.32 \mathrm{~mm}$, and rebar outside of the sleeve fracture finally happens. The finite element curve and the experimental curve are basically coincided before the rebar yield; after the rebar yield, an ideal trifold line model is used for the constitutive relation of rebars and the strengthening stage is a straight line, while the actual strengthening stage of the rebar should be a convex curve. As a result, the finite element load-slip curves and the experimental curves were fundamentally in consilience despite slight differences in the strengthening stage. Therefore, this is a grout sleeve splicing rebar model with a reference value.

As can be seen in the analysis results of the finite element stimulation in Figure 8, the largest part of the whole joint is on the connecting rebar outside the sleeve and then the stress on the sleeve; in contrast, the grouting material receives less stress. The stress on the lower part of the connecting rebar gradually increases from top to bottom, the part without grout wrap is very evident, the stress sharply grows, and it finally leads to fracture; the maximum stress is $588 \mathrm{MPa}$. The stress of the grouting material gradually grows from the axial stress contacts sleeve to rebar, and the maximum stress is 387.39 MPa. Experiment and stimulation data of the control group are shown in Table 4.

4.2. The Insufficient Grout Height Specimen. The load-slip curves of vertical insufficient grouting height specimen are shown in Figure 9. The experimental results were excluded because of the error of specimen 3 in the process of load application. The load-slip curves are still evidently present in four stages compared with the control group (reference group AVG); ultimate load drops from $119.73 \mathrm{kN}$ to $115.02 \mathrm{kN}$ and $114.58 \mathrm{kN}$, and bond slip decreases from $7.32 \mathrm{~mm}$ to $7.14 \mathrm{~mm}$ and $7.29 \mathrm{~mm}$, which explains that the sleeve bearing capacity descends and the bond slipped displacement decreases. The finite element stimulation of the load-slip curves and the results of the experiment basically coincides; however, the result of the fourth stage appears as obvious falling branch. The experiment and stimulation data

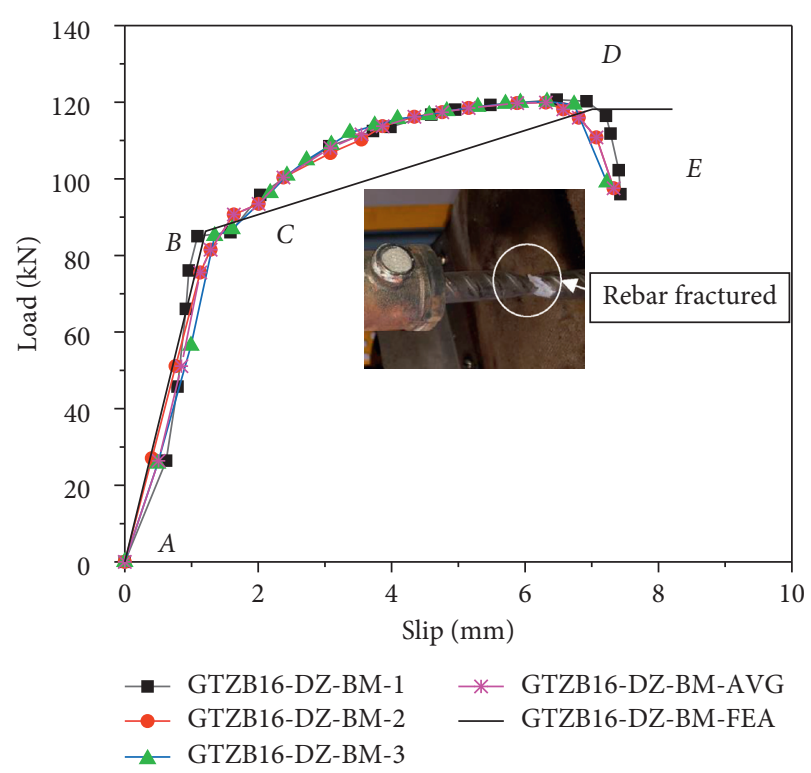

FIgURE 7: The load-slip curves of the control group (AVG: average value; FEA: finite element analysis).

of vertical insufficient grouting height specimen can be seen in Table 5.

From the results of the finite element stimulation analysis in Figure 10, the rebar stress value of sleeve cavity is the smallest and not affected by the bond stress of the grouting material. The stress of the lower part of rebars is the largest and develops, which coincides with the experimental destruction. The grouting stress increases from $91.85 \mathrm{MPa}$ to 97.91 MPa, which indicates the stress on grouting materials grows in the condition of insufficient grouting height. The sleeve stress on top maximizes, the grip strength is not enough to anchor rebars, and the specimen may have the condition of rebar extraction mentioned above.

We applied the finite element software to make stimulation analysis (see Figure 11) of the rebar anchoring with the height of $88 \mathrm{~mm}(5.5 \mathrm{~d})$ in order to discover the influence critical value of the insufficient grouting height. The results of the experiment show that the bearing capacity of grouting sleeve joint drops to $536.62 \mathrm{MPa}$ when the grouting height is $88 \mathrm{~mm}$ (5.5 d), which does not meet the requirement of the tensile strength. As a result, $88 \mathrm{~mm}(5.5 \mathrm{~d})$ of the grouting height is an extremely significant critical value.

4.3. The Insufficient Compactness Specimen. The insufficient compactness specimen is the grouting material filled up with $20 \%$ of foam particles, the destruction model of joints-rebar break turns to rebar extraction, and the slip decreases from $7.32 \mathrm{~mm}$ to $4.24 \mathrm{~mm}, 3.71 \mathrm{~mm}$, and $4.20 \mathrm{~mm}$. It can be seen from the load-slip curves (see Figure 12) that the elastic stage (stage $\mathrm{AB}$ ) and the yield stage (stage $\mathrm{BC}$ ) are basically coinciding with the control group curves. When the joint develops into the strengthening stage, the anchoring capacity is not enough to bear the weight of tensile strength; rebar extraction destruction suddenly happens, which leads to joint damage before the necking stage. The ultimate load 


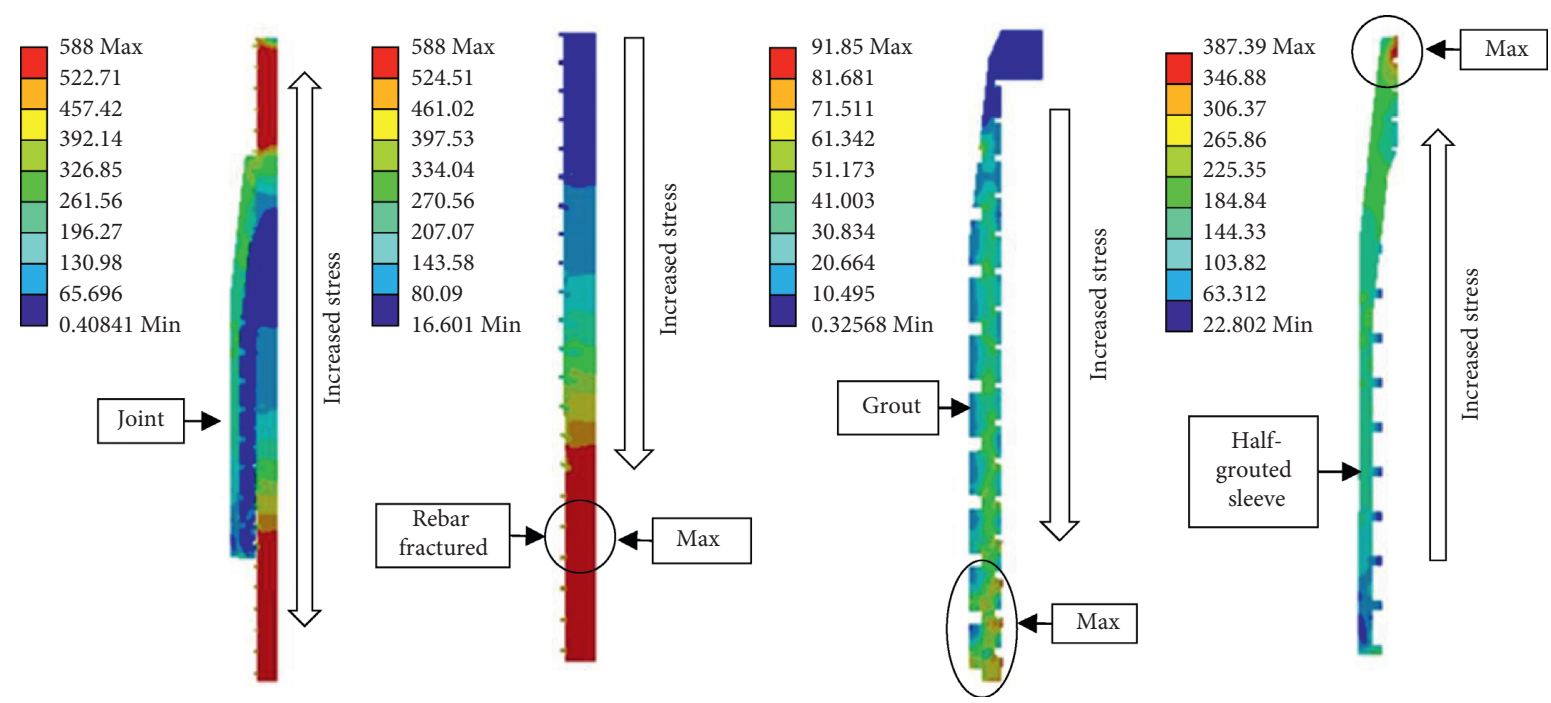

FIgURE 8: The finite element stimulation stress distribution diagram of the control group (unit: MPa).

TABLE 4: Experiment and stimulation results of the control group.

\begin{tabular}{|c|c|c|c|c|c|c|c|}
\hline Type & Specimen number & $\begin{array}{l}\text { Ultimate load } \\
(\mathrm{kN})\end{array}$ & $\begin{array}{c}\text { Rebar stress } \\
(\mathrm{MPa})\end{array}$ & $\begin{array}{c}\text { Lower yield } \\
(\mathrm{kN})\end{array}$ & $\begin{array}{l}\text { Yield strength } \\
(\mathrm{MPa})\end{array}$ & $\begin{array}{c}\text { Slip } \\
(\mathrm{mm})\end{array}$ & Destruction mode \\
\hline \multirow{3}{*}{ A } & GTZB16-DZ-BM-1 & 120.66 & 600.00 & 81.50 & 405.27 & 7.43 & $\begin{array}{l}\text { Rebar tension } \\
\text { fracture }\end{array}$ \\
\hline & GTZB16-DZ-BM-2 & 119.74 & 595.43 & 90.18 & 448.43 & 7.32 & $\begin{array}{l}\text { Rebar tension } \\
\text { fracture }\end{array}$ \\
\hline & GTZB16-DZ-BM-3 & 120.16 & 597.51 & 90.38 & 449.43 & 7.22 & $\begin{array}{l}\text { Rebar tension } \\
\text { fracture }\end{array}$ \\
\hline AVG & $\begin{array}{c}\text { GTZB16-DZ-BM- } \\
\text { AVG }\end{array}$ & 119.73 & 595.67 & 87.35 & 434.59 & 7.32 & $\begin{array}{l}\text { Rebar tension } \\
\text { fracture }\end{array}$ \\
\hline FEA & $\begin{array}{c}\text { GTZB16-DZ-BM- } \\
\text { FEA }\end{array}$ & 118.19 & 588.00 & 86.31 & 429.40 & 7.01 & $\begin{array}{l}\text { Rebar tension } \\
\text { fracture }\end{array}$ \\
\hline
\end{tabular}

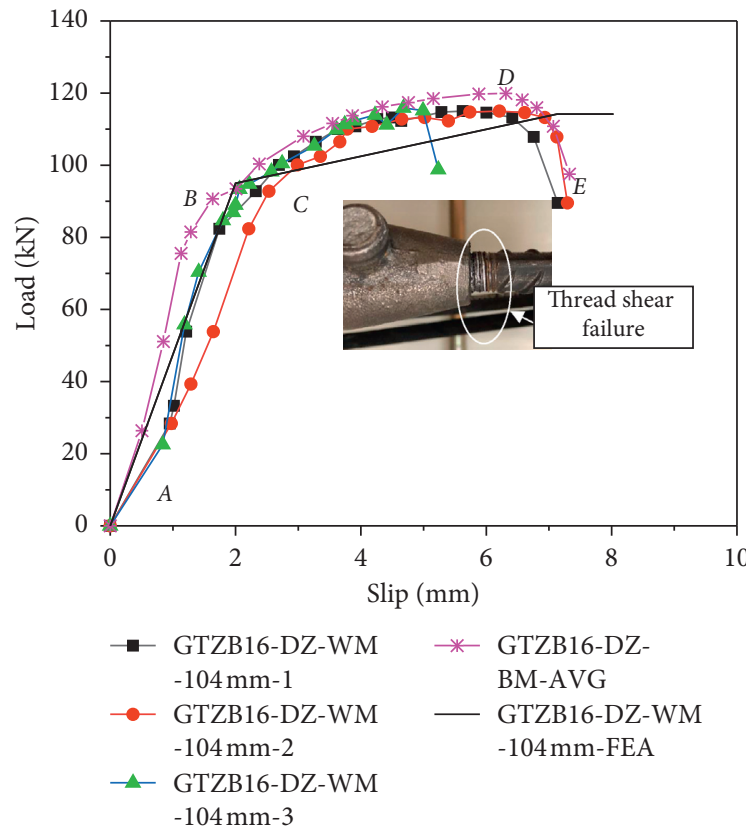

Figure 9: The load-slip curves of insufficient grout height specimen (104 mm: 6.5 d; AVG: average value; FEA: finite element analysis). decreases from $119.73 \mathrm{kN}$ to $113.02 \mathrm{kN}, 113.86 \mathrm{kN}$, and $110.04 \mathrm{kN}$. Consequently, insufficient compactness will lead to the decline in bearing capacity and deformation performance.

3D models are used to stimulate insufficient compactness specimen (see Figure 13). The overall stress of the joint gradually and vertically grows from the outlet hole to both ends, and the rebar stress outside the sleeve sharply rises. The load stress of the grouting material at the bottom of the sleeve gradually increases to $91.75 \mathrm{MPa}$; rebar extraction and peeling of the grouting material eventually occurs. Experiment and stimulation data are shown in Table 6.

4.4. Rebar Offset Joints. The rebar at the lower part of the rebar offset joint is closely stuck to the sleeve wall and kept away from the inlet and one side of the outlet hole in order to avoid the effect of the grouting. As can be seen in Figure 14, the experiment and load-slip curves stimulation are basically coincided, and there are some branches on the descending part. The destruction result shows that the rebar above is broken because the eccentricity of the rebar connected is subjected to the greatest lateral force (see Figure 15), the 
TABLE 5: The experiment and stimulation data of the insufficient grouting height specimen (104 mm: $6.5 \mathrm{~d})$.

\begin{tabular}{|c|c|c|c|c|c|c|c|}
\hline Type & Specimen number & $\begin{array}{l}\text { Ultimate load } \\
(\mathrm{kN})\end{array}$ & $\begin{array}{l}\text { Rebar stress } \\
(\mathrm{MPa})\end{array}$ & $\begin{array}{c}\text { Lower yield } \\
(\mathrm{kN})\end{array}$ & $\begin{array}{l}\text { Yield strength } \\
(\mathrm{MPa})\end{array}$ & $\begin{array}{l}\text { Slip } \\
(\mathrm{mm})\end{array}$ & Destruction mode \\
\hline \multirow{3}{*}{ B } & $\begin{array}{l}\text { GTZB16-DZ-WM- } \\
104 \mathrm{~mm}-1\end{array}$ & 115.02 & 571.95 & 83.68 & 416.11 & 7.14 & $\begin{array}{l}\text { Rebar tension } \\
\text { fracture }\end{array}$ \\
\hline & $\begin{array}{l}\text { GTZB16-DZ-WM- } \\
104 \mathrm{~mm}-2\end{array}$ & 114.58 & 569.77 & 86.64 & 430.83 & 7.29 & $\begin{array}{l}\text { Rebar tension } \\
\text { fracture }\end{array}$ \\
\hline & $\begin{array}{c}\text { GTZB16-DZ-WM- } \\
104 \mathrm{~mm}-3\end{array}$ & 115.88 & 569.77 & 86.48 & 430.03 & 5.32 & - tar \\
\hline $\mathrm{AVG}$ & GTZB16-DZ-BM-AVG & 119.73 & 595.67 & 87.35 & 434.59 & 7.32 & $\begin{array}{l}\text { Rebar tension } \\
\text { fracture }\end{array}$ \\
\hline FEA & $\begin{array}{c}\text { GTZB16-DZ-WM- } \\
100 \mathrm{~mm}-\mathrm{FEA}\end{array}$ & 114.17 & 568.00 & 85.94 & 427.56 & 7.13 & $\begin{array}{c}\text { Rebar tension } \\
\text { fracture }\end{array}$ \\
\hline
\end{tabular}

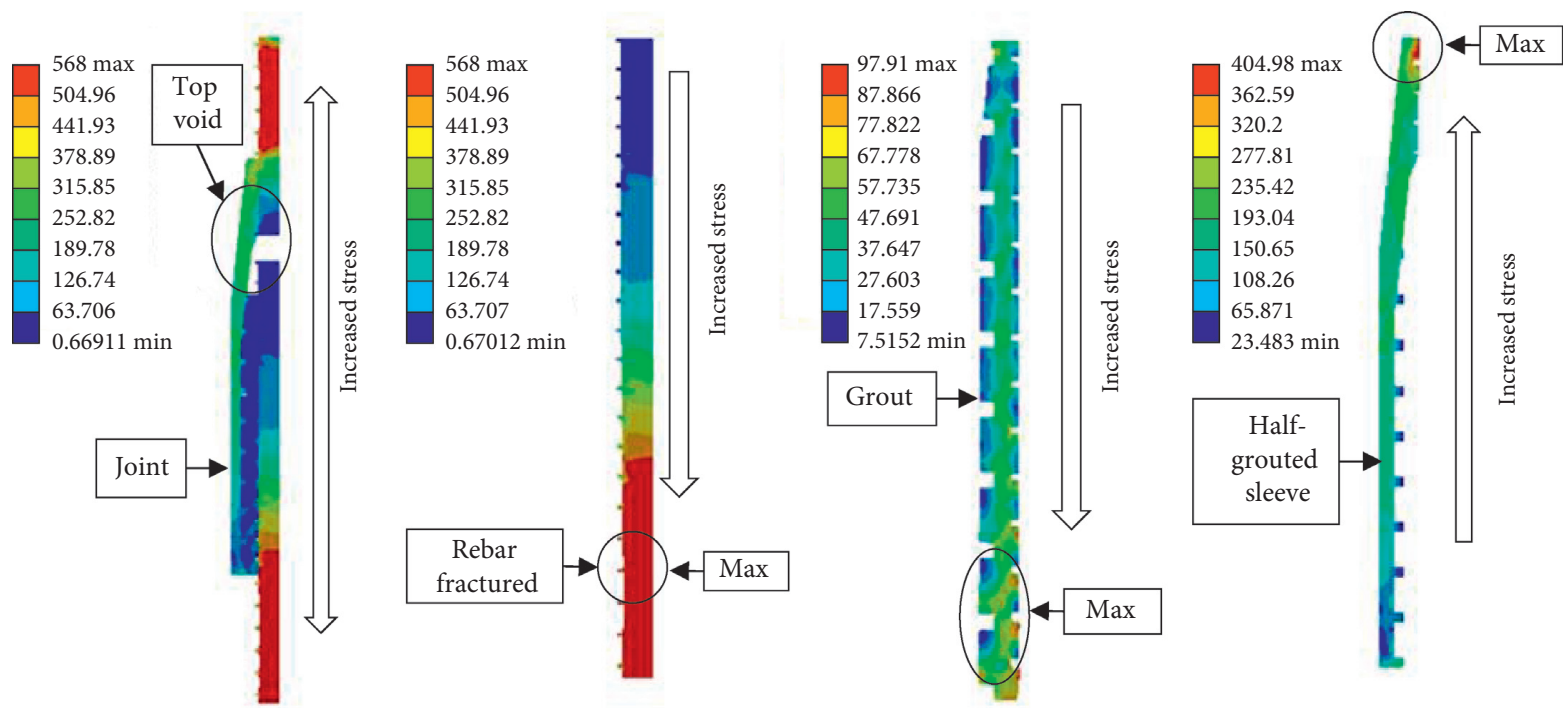

Figure 10: The finite element stimulation stress distribution diagram of the vertical insufficient grouting height specimen (104 mm: $6.5 \mathrm{~d}$, unit: $\mathrm{MPa})$.
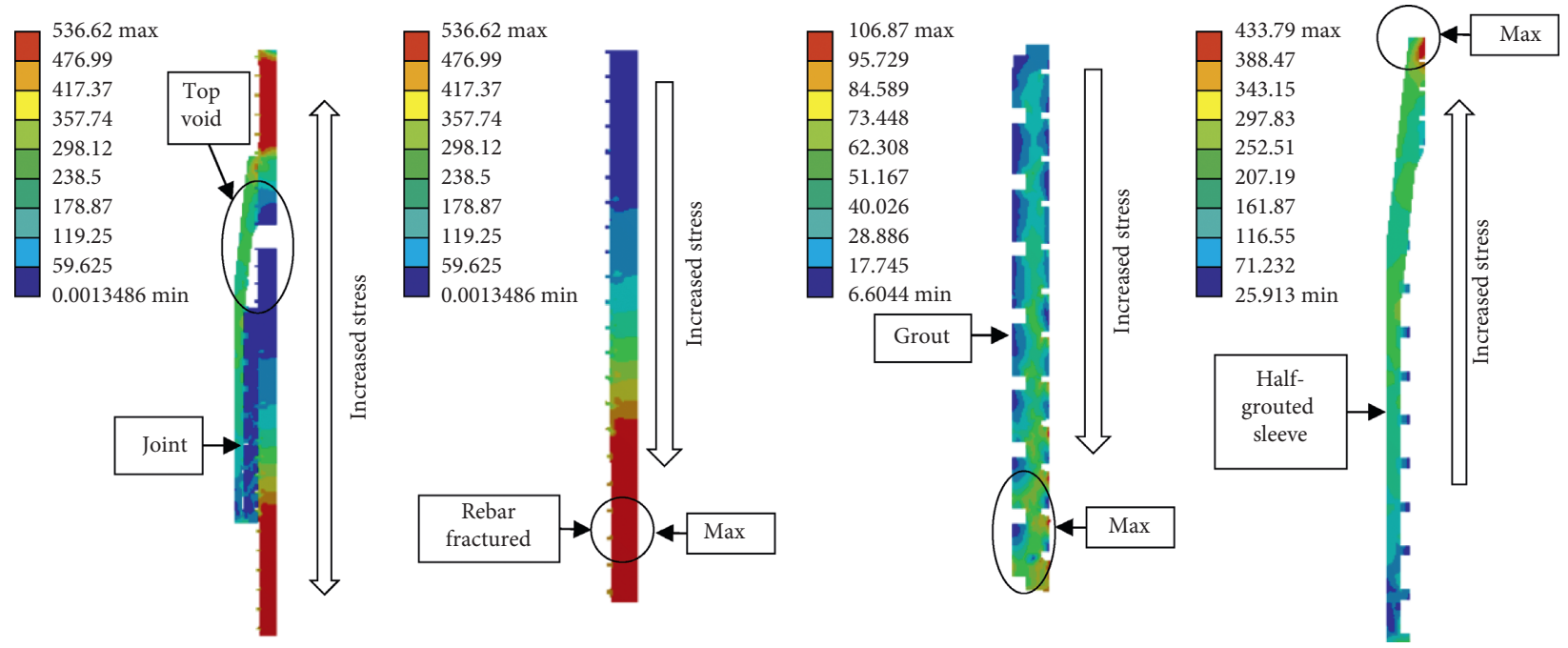

FIGURE 11: The finite element stimulation stress distribution diagram of the vertical insufficient grout height specimen $(88 \mathrm{~mm}$ : $5.5 \mathrm{~d}$; unit: $\mathrm{MPa})$. 


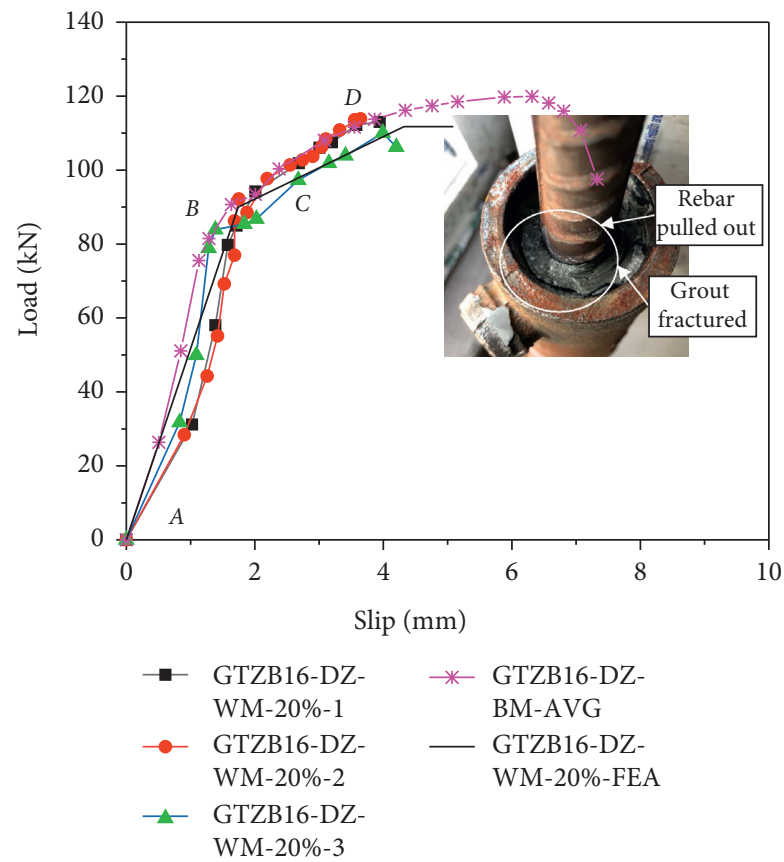

Figure 12: The load-slip curves of the insufficient compactness specimen (AVG: average value; FEA: finite element analysis).

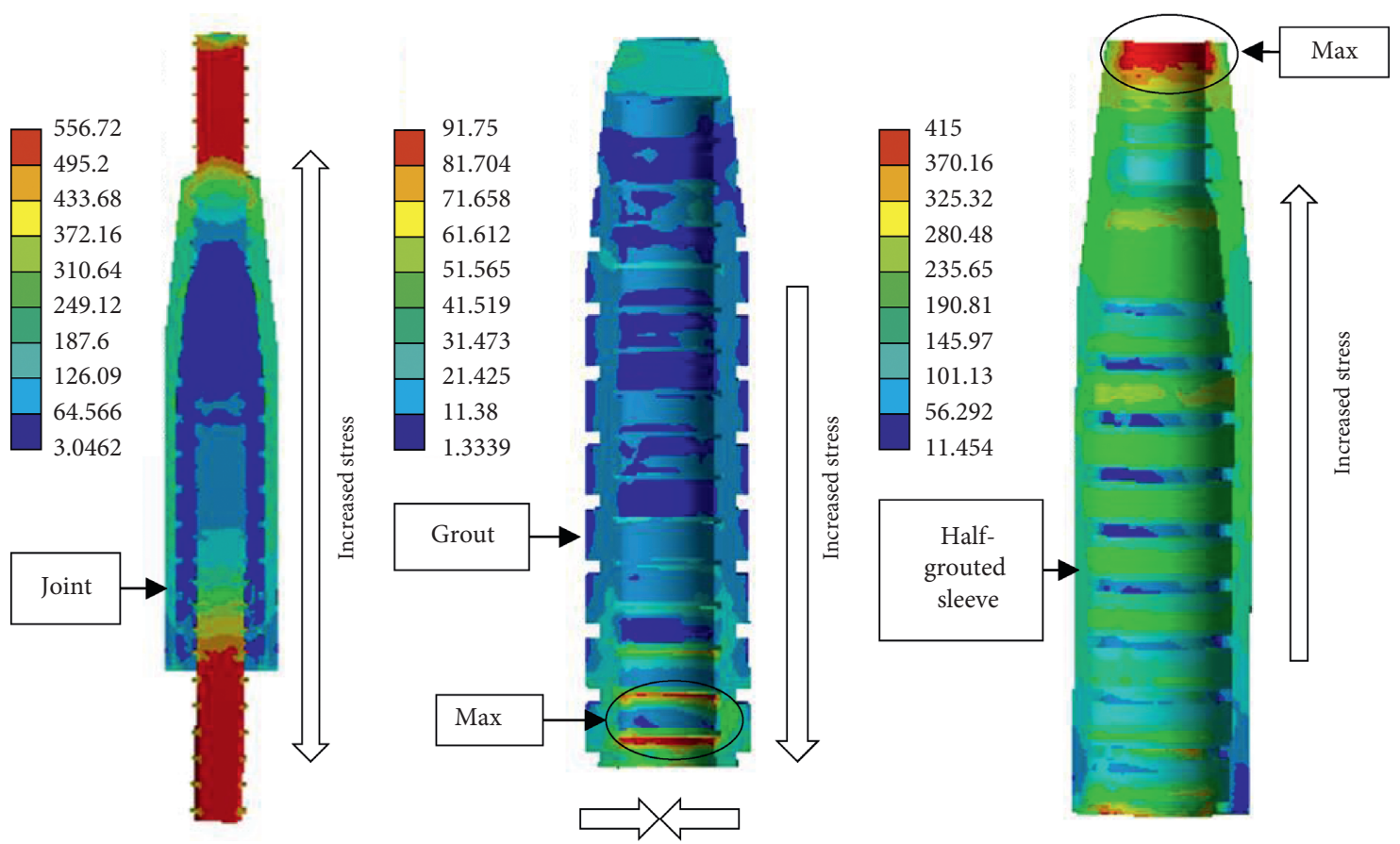

FIgURE 13: The finite element stimulation stress distribution diagram of the insufficient compactness specimen (unit: MPa).

lower rebar decreased rapidly with the increasing eccentricity, and the lateral force of the grouting material and the sleeve increases with the eccentricity, which are all in reasonable ranges. Ultimate load falls from $19.93 \mathrm{kN}$ to $115.76 \mathrm{kN}$ and $114.28 \mathrm{kN}$ (see Table 7); slip drops from $7.32 \mathrm{~mm}$ to $6.99 \mathrm{~mm}, 6.74 \mathrm{~mm}$, and $6.98 \mathrm{~mm}$, which indicates that the bearing capacity slightly descends and the slip decreases as the rebar eccentricity increases.
4.5. The Insufficient Rebar Anchor Length Specimen. The experiment and stimulation results from the insufficient anchoring length specimen are very close (see Figure 16), and the load-slip curves are basically coincided. As it can be seen in Figure 17, the rebar stress gradually decreases as the rebar penetration reduces, and the rebar fracture turns to rebar extraction destruction. On the contrary, the grouting stress raises from 94.34 $\mathrm{MPa}$ to $110.24 \mathrm{MPa}$ and sleeve stress 
TABLE 6: Experiment and stimulation data of the insufficient compactness specimen.

\begin{tabular}{|c|c|c|c|c|c|c|c|}
\hline Type & Specimen number & $\begin{array}{c}\text { Ultimate load } \\
(\mathrm{kN})\end{array}$ & $\begin{array}{l}\text { Rebar stress } \\
\text { (MPa) }\end{array}$ & $\begin{array}{c}\text { Lower yield } \\
(\mathrm{kN})\end{array}$ & $\begin{array}{l}\text { Yield strength } \\
(\mathrm{MPa})\end{array}$ & $\begin{array}{l}\text { Slip } \\
(\mathrm{mm})\end{array}$ & Destruction mode \\
\hline \multirow{3}{*}{$\mathrm{C}$} & $\begin{array}{c}\text { GTZB16-DZ-WM- } \\
20 \%-1\end{array}$ & 113.02 & 562.28 & 79.76 & 396.82 & 4.24 & Rebar pullout \\
\hline & $\begin{array}{c}\text { GTZB16-DZ-WM- } \\
20 \%-2\end{array}$ & 113.86 & 566.47 & 83.90 & 417.21 & 3.71 & Rebar pullout \\
\hline & $\begin{array}{c}\text { GTZB16-DZ-WM- } \\
20 \%-3\end{array}$ & 110.04 & 547.46 & 83.92 & 417.51 & 4.20 & Rebar pullout \\
\hline AVG & GTZB16-DZ-BM-AVG & 119.73 & 595.67 & 87.35 & 434.59 & 7.32 & $\begin{array}{l}\text { Rebar tension } \\
\text { fracture }\end{array}$ \\
\hline FEA & $\begin{array}{c}\text { GTZB16-DZ-WM- } \\
\text { 20\%-FEA }\end{array}$ & 111.90 & 556.72 & 89.97 & 447.61 & 4.42 & Rebar pullout \\
\hline
\end{tabular}

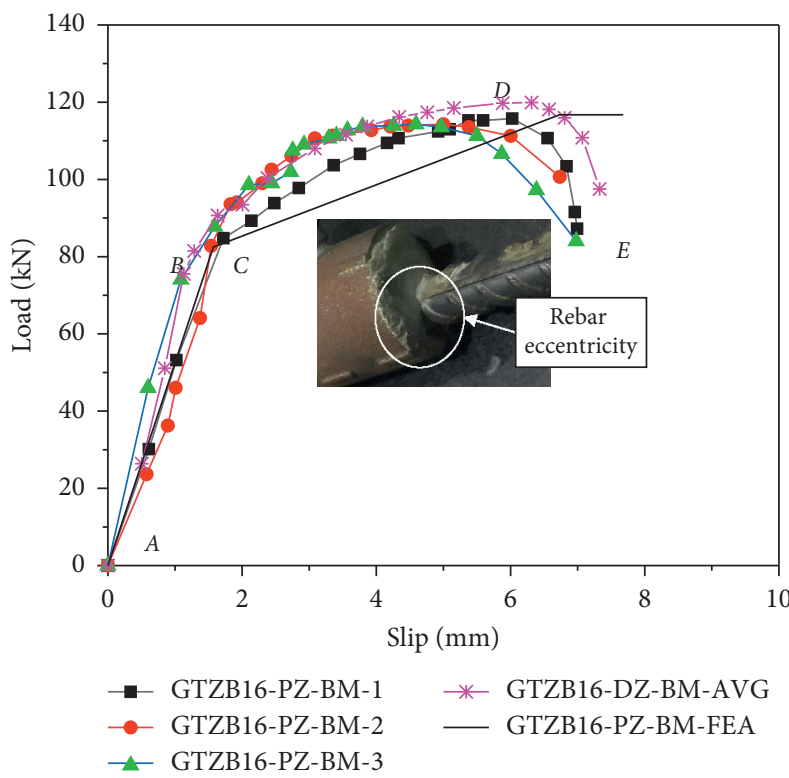

Figure 14: The load-slip curves of the rebar offset specimen (AVG: average value; FEA: finite element analysis).
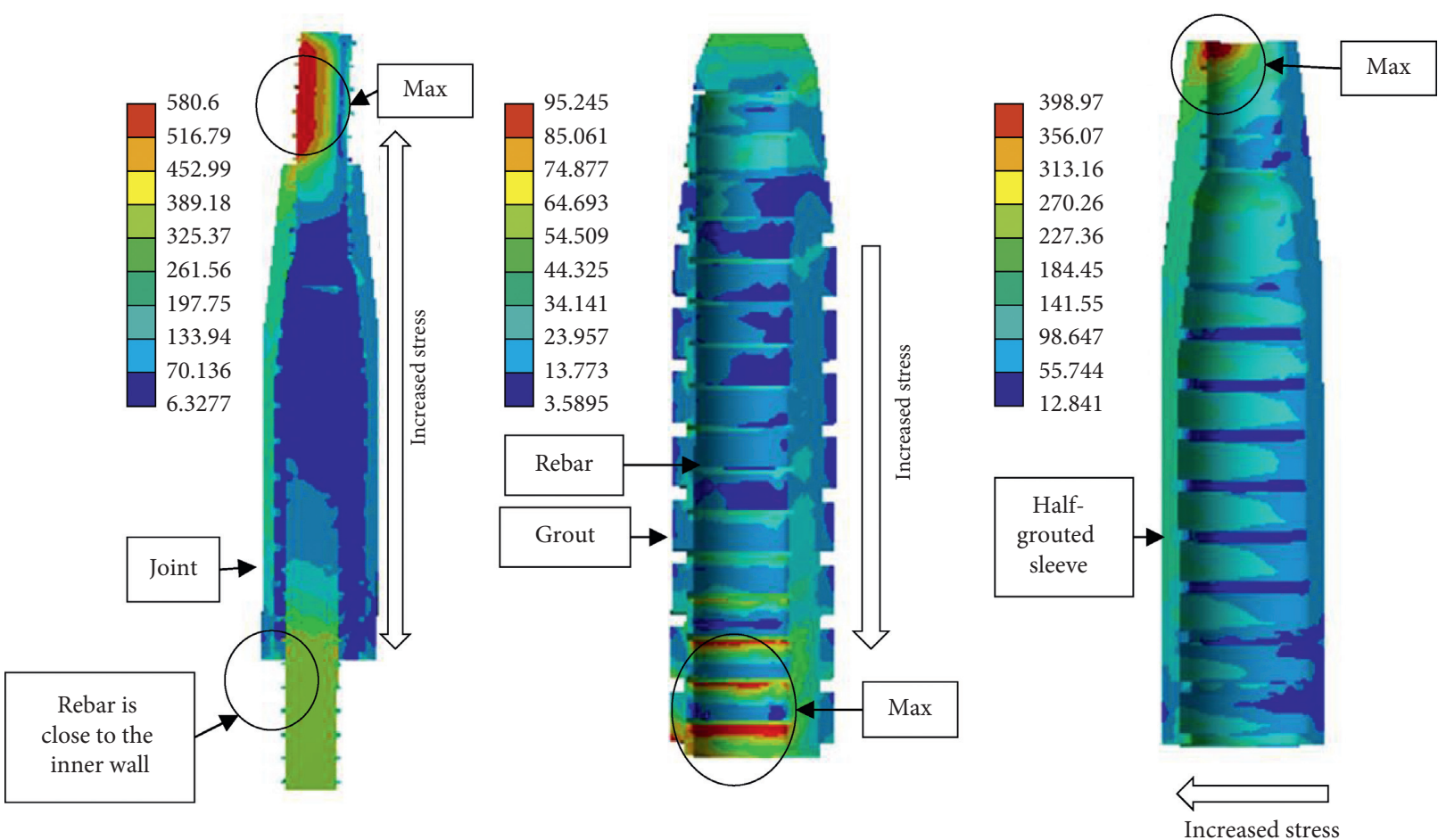

FIgURE 15: The finite element stimulation stress distribution diagram of the rebar offset specimen (unit: MPa). 
TABLE 7: Experiment and stimulation data of the rebar offset joint specimen.

\begin{tabular}{|c|c|c|c|c|c|c|c|}
\hline Type & Specimen number & $\begin{array}{l}\text { Ultimate load } \\
\qquad(\mathrm{kN})\end{array}$ & $\begin{array}{l}\text { Rebar stress } \\
(\mathrm{MPa})\end{array}$ & $\begin{array}{c}\text { Lower yield } \\
(\mathrm{kN})\end{array}$ & $\begin{array}{l}\text { Yield strength } \\
(\mathrm{MPa})\end{array}$ & $\begin{array}{l}\text { Slip } \\
(\mathrm{mm})\end{array}$ & Destruction mode \\
\hline \multirow{3}{*}{$\mathrm{D}$} & GTZB16-PZ-BM-1 & 115.76 & 575.92 & 84.76 & 421.69 & 6.99 & $\begin{array}{l}\text { Rebar tension } \\
\text { fracture }\end{array}$ \\
\hline & GTZB16-PZ-BM-2 & 114.28 & 568.56 & 82.80 & 411.94 & 6.74 & $\begin{array}{l}\text { Rebar tension } \\
\text { fracture }\end{array}$ \\
\hline & GTZB16-PZ-BM-3 & 114.28 & 568.56 & 87.41 & 434.88 & 6.98 & $\begin{array}{l}\text { Rebar tension } \\
\text { fracture }\end{array}$ \\
\hline $\mathrm{AVG}$ & $\begin{array}{c}\text { GTZB16-DZ-BM- } \\
\text { AVG }\end{array}$ & 119.73 & 595.67 & 87.35 & 434.59 & 7.32 & $\begin{array}{c}\text { Rebar tension } \\
\text { fracture }\end{array}$ \\
\hline FEA & $\begin{array}{c}\text { GTZB16-PZ-BM- } \\
\text { FEA }\end{array}$ & 116.76 & 580.60 & 82.49 & 410.40 & 6.73 & $\begin{array}{l}\text { Rebar tension } \\
\text { fracture }\end{array}$ \\
\hline
\end{tabular}

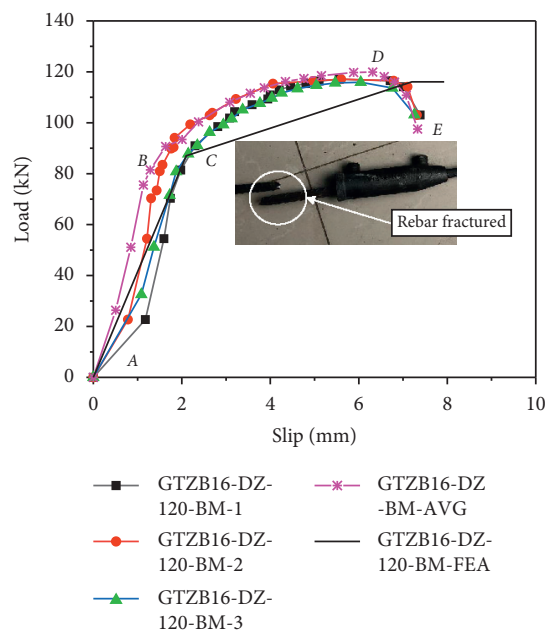

(a)

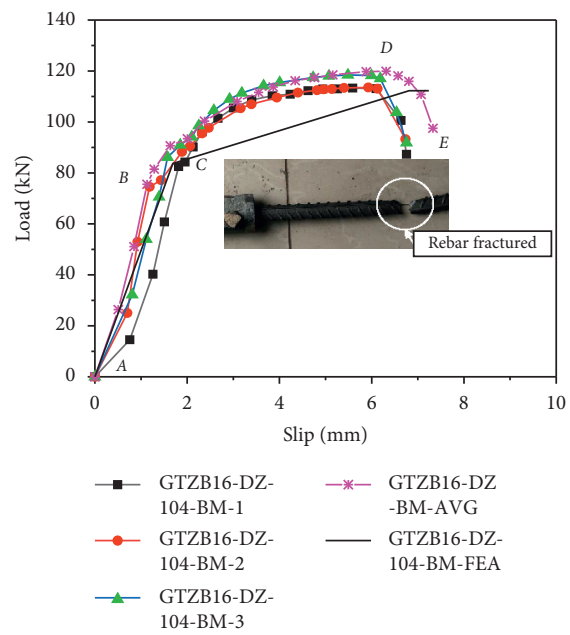

(b)

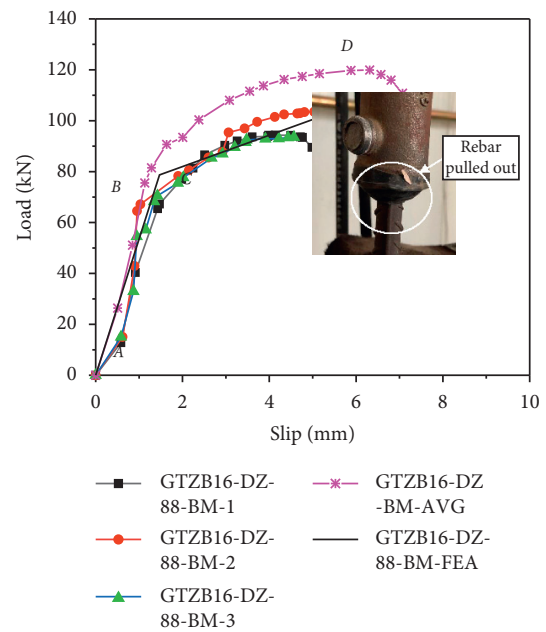

(c)

FIGURE 16: The load-slip curves of the insufficient rebar anchor length specimen (AVG: average value; FEA: finite element analysis). Rebar anchor: (a) $120 \mathrm{~mm}$ (7.5 d); (b) $104 \mathrm{~mm}$ (6.5 d); (c) $88 \mathrm{~mm}$ (5.5 d).

from 401.34 MPa to $424.37 \mathrm{MPa}$ (see Table 8 ) as the decline of rebar anchoring length. The compressive resistance and yield strength are still in reasonable ranges when rebar anchoring length successively decreases from $130 \mathrm{~mm}(8 \mathrm{~d})$ to $120 \mathrm{~mm}(7.5 \mathrm{~d})$ and $104 \mathrm{~mm}(6.5 \mathrm{~d})$. The bonding strength of the grouting material does not meet the compressive resistance, and the rebar and the grouting material are pulled out simultaneously with a little peel off the grouting material.

4.6. The Overtime Grouting Specimen. We applied the no finite element stimulation because the grouting constitutive model is not well-developed yet. After 30 minutes of grouting, the grouting fluidity decreases because of hydration, which makes the possibility of blockage grows when grouting. As shown in Figure 18, the elastic stage (stage AB), the yield stage (stage $\mathrm{BC}$ ), the strengthening stage (stage $\mathrm{CD}$ ), and the necking stage (stage DE) basically coincide. As shown in Table 9, the ultimate load decreases from $119.73 \mathrm{kN}$ to $117.62 \mathrm{kN}, 117.46 \mathrm{kN}$, and $115.38 \mathrm{kN}$, while the bearing capacity is still in a reasonable range.

\section{Discussion}

Different degrees of defects of grouting sleeve joints significantly affect the safety of the prefabricated component connection. To better understand the force performance in different circumstances of defects of the grouting sleeve joints, uniaxial tension experiments and finite element stimulation analysis of 24 specimens were done. As shown in Table $10, P_{u}^{\prime}$ and $P_{y}^{\prime}$, respectively, represent the ultimate load and yield load from the finite element analysis, $P_{y}$ is the yield load from the experiment, and $P_{u}$ is the bearing capacity when the rebar breaks or extracts. The results of the load-slip curves between the control group and the defect specimen are very close, which are below $3 \%$, except $P_{u}^{\prime} / P_{u}$ of GTZB16-DZ-88 $\mathrm{mm}$ is $5 \%$, with a minimum $1 \%$ of error. As a result, analysis approaches of this research could provide bearing capacity results that meet accuracy requirements.

As shown in Figure 19, for the comparison of the bearing capacity of the five defective specimens with the reference group, the upper limit (blue line) is the average rebar stress of the standard specimen $595.67 \mathrm{MPa}$, and the lower limit (grey line) is the standard value of tensile strength of 

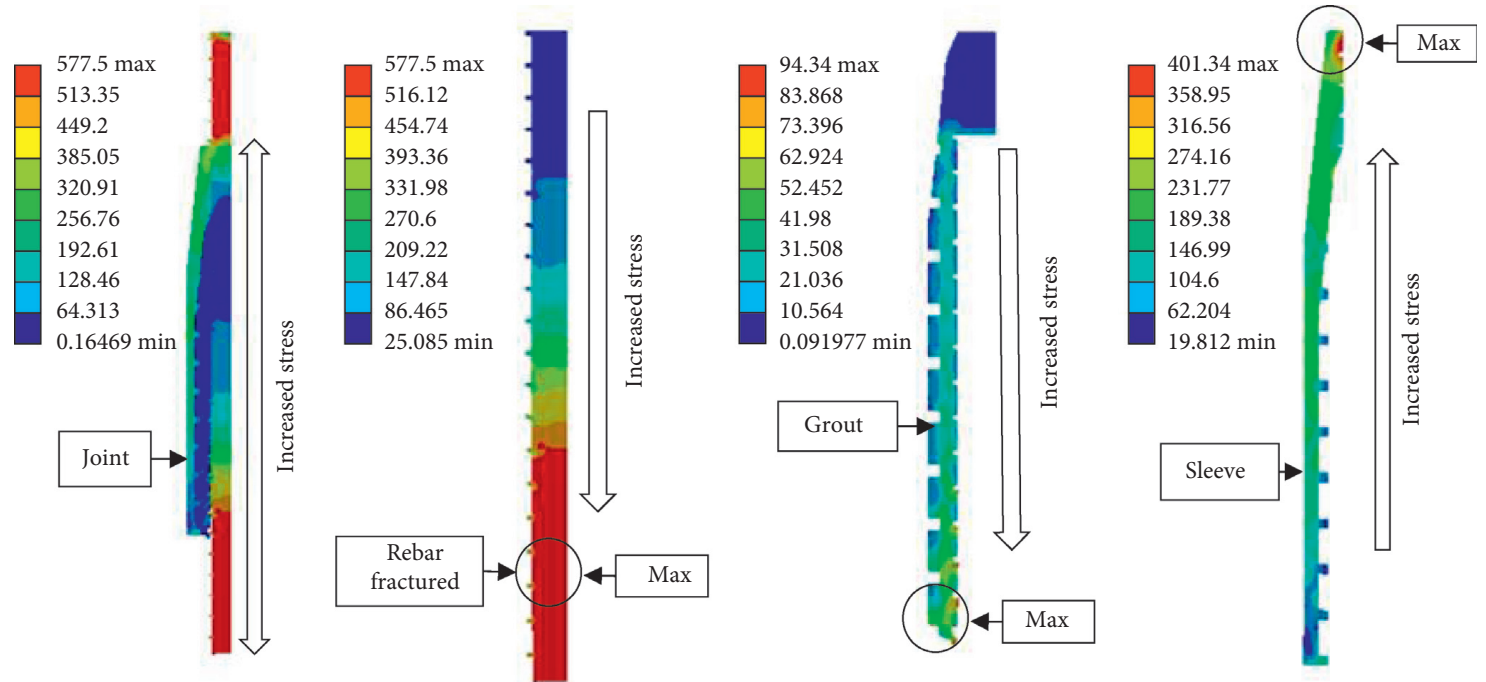

(a)
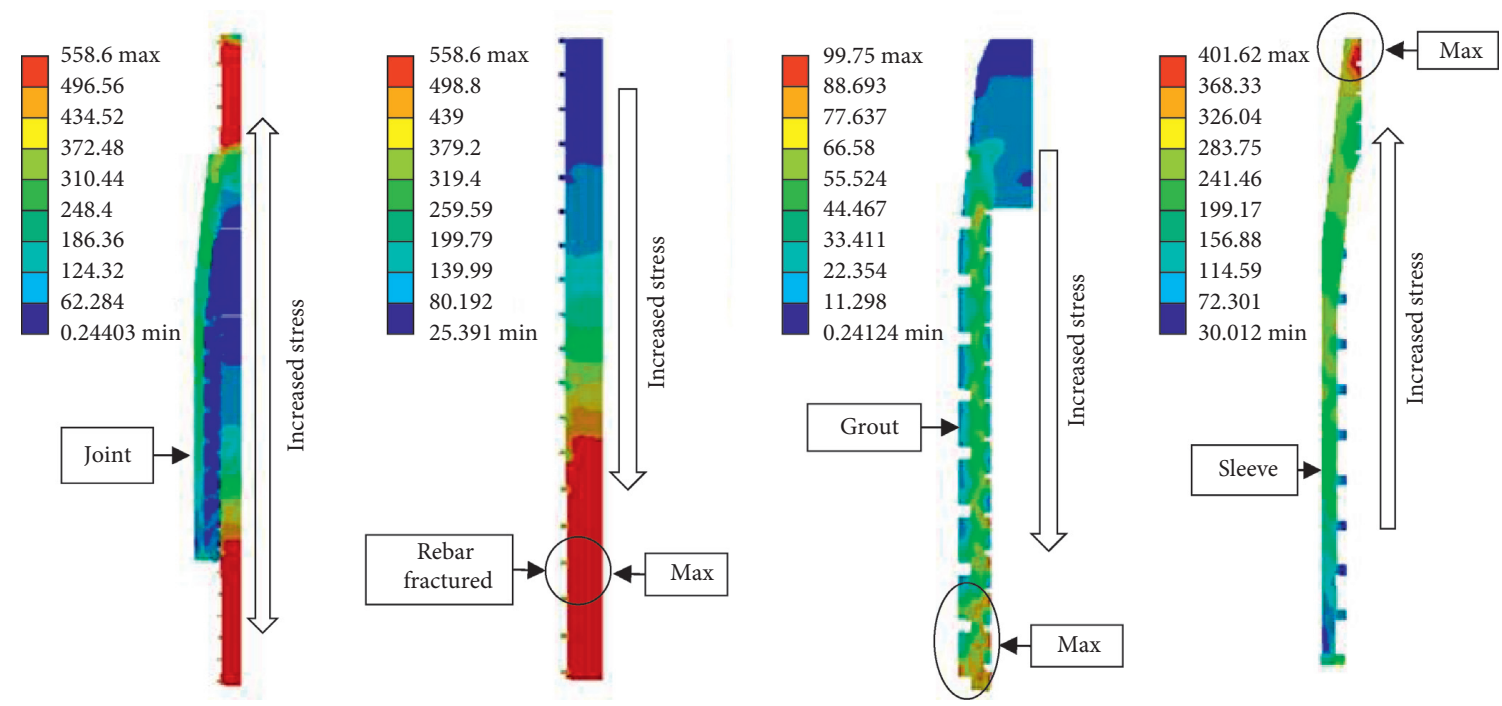

(b)
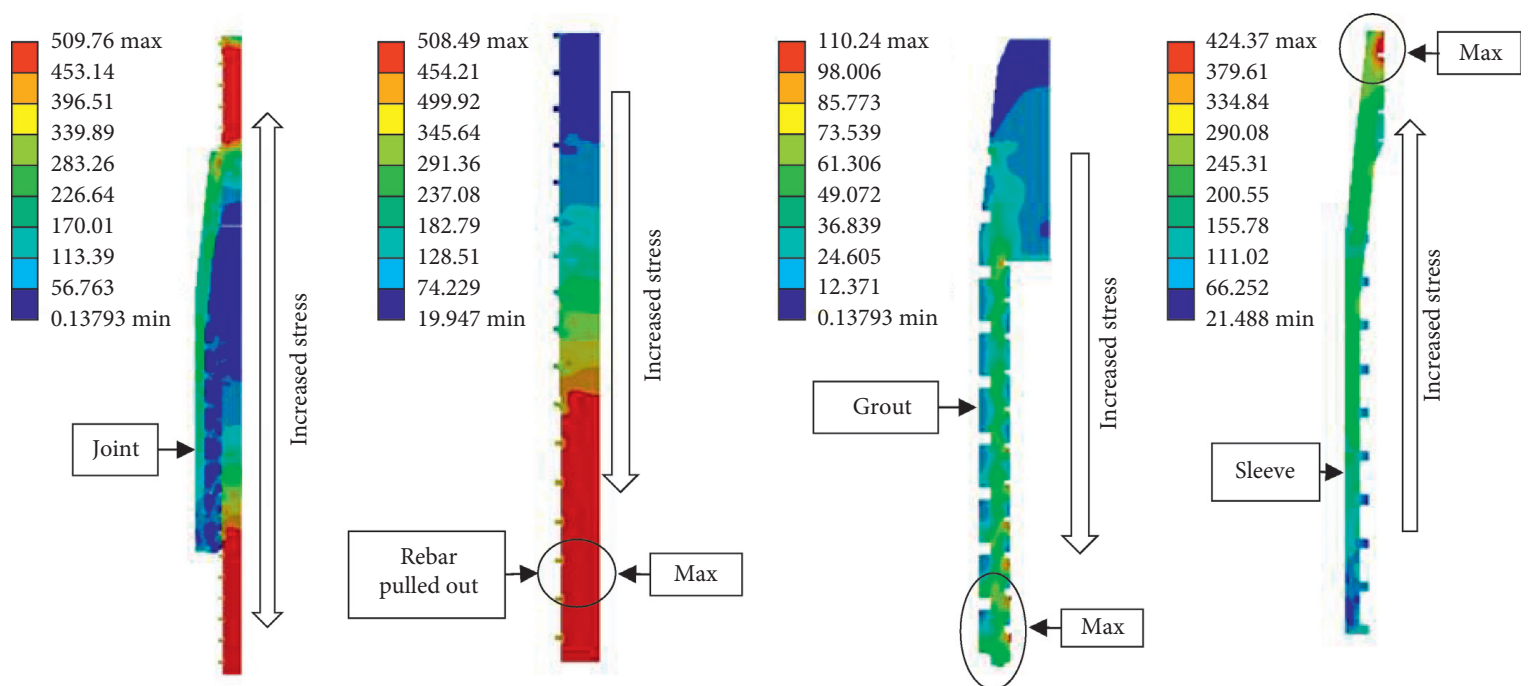

(c)

FIgURE 17: The finite element stimulation stress distribution diagram of the insufficient rebar anchor length specimen (unit: MPa). Rebar anchor: (a) $120 \mathrm{~mm}$ (7.5 d); (b) $104 \mathrm{~mm}$ (6.5 d); (c) $88 \mathrm{~mm}$ (5.5 d). 
TABLE 8: The experiment and stimulation data of the insufficient anchoring length specimen.

\begin{tabular}{|c|c|c|c|c|c|c|c|}
\hline Type & Specimen number & $\begin{array}{l}\text { Ultimate load } \\
(\mathrm{kN})\end{array}$ & $\begin{array}{l}\text { Rebar stress } \\
(\mathrm{MPa})\end{array}$ & $\begin{array}{c}\text { Lower yield } \\
(\mathrm{kN})\end{array}$ & $\begin{array}{l}\text { Yield strength } \\
(\mathrm{MPa})\end{array}$ & $\begin{array}{l}\text { Slip } \\
(\mathrm{mm})\end{array}$ & Destruction mode \\
\hline \multirow{3}{*}{ E1 } & $\begin{array}{c}\text { GTZB16-DZ-120 mm- } \\
\text { BM-1 }\end{array}$ & 117.12 & 582.40 & 86.43 & 429.79 & 7.39 & $\begin{array}{l}\text { Rebar tension } \\
\text { fracture }\end{array}$ \\
\hline & $\begin{array}{c}\text { GTZB16-DZ-120 mm- } \\
\text { BM-2 }\end{array}$ & 117.38 & 583.69 & 85.48 & 425.06 & 7.31 & $\begin{array}{l}\text { Rebar tension } \\
\text { fracture }\end{array}$ \\
\hline & $\begin{array}{c}\text { GTZB16-DZ-120 mm- } \\
\text { BM-3 }\end{array}$ & 115.9 & 576.33 & 80.83 & 401.94 & 7.26 & $\begin{array}{l}\text { Rebar tension } \\
\text { fracture }\end{array}$ \\
\hline \multirow{2}{*}{ FEA 1} & $\begin{array}{c}\text { GTZB16-DZ-120 mm- } \\
\text { BM-FEA }\end{array}$ & 116.07 & 577.18 & 87.05 & 432.87 & 7.20 & $\begin{array}{l}\text { Rebar tension } \\
\text { fracture }\end{array}$ \\
\hline & $\begin{array}{c}\text { GTZB16-DZ-104 mm- } \\
\text { BM-1 }\end{array}$ & 113.30 & 563.40 & 82.48 & 410.14 & 6.75 & $\begin{array}{l}\text { Rebar tension } \\
\text { fracture }\end{array}$ \\
\hline \multirow{2}{*}{ E2 } & $\begin{array}{c}\text { GTZB16-DZ-104 mm- } \\
\text { BM-2 }\end{array}$ & 113.52 & 564.50 & 77.16 & 383.69 & 6.73 & $\begin{array}{l}\text { Rebar tension } \\
\text { fracture }\end{array}$ \\
\hline & $\begin{array}{c}\text { GTZB16-DZ-104 mm- } \\
\text { BM-3 }\end{array}$ & 118.46 & 589.06 & 86.15 & 428.39 & 6.76 & $\begin{array}{l}\text { Rebar tension } \\
\text { fracture }\end{array}$ \\
\hline \multirow{2}{*}{ FEA 2} & $\begin{array}{c}\text { GTZB16-DZ-104 mm- } \\
\text { BM-FEA }\end{array}$ & 112.28 & 558.33 & 83.69 & 416.16 & 6.81 & $\begin{array}{l}\text { Rebar tension } \\
\text { fracture }\end{array}$ \\
\hline & $\begin{array}{c}\text { GTZB16-DZ-88 mm- } \\
\text { BM-1 }\end{array}$ & 94.38 & 469.32 & 67.26 & 334.46 & 4.98 & Rebar pullout \\
\hline \multirow{2}{*}{ E3 } & $\begin{array}{c}\text { GTZB16-DZ-88 mm- } \\
\text { BM-2 }\end{array}$ & 103.52 & 514.77 & 64.54 & 320.93 & 5.03 & Rebar pullout \\
\hline & $\begin{array}{c}\text { GTZB16-DZ-88 mm- } \\
\text { BM-3 }\end{array}$ & 93.52 & 465.04 & 68.26 & 339.43 & 4.57 & Rebar pullout \\
\hline FEA 3 & $\begin{array}{c}\text { GTZB16-DZ-88 mm- } \\
\text { BM-FEA }\end{array}$ & 102.46 & 509.50 & 78.7 & 391.35 & 5.32 & Rebar pullout \\
\hline $\mathrm{AVG}$ & GTZB16-DZ-BM-AVG & 119.73 & 595.67 & 87.35 & 434.59 & 7.32 & $\begin{array}{l}\text { Rebar tension } \\
\text { fracture }\end{array}$ \\
\hline
\end{tabular}

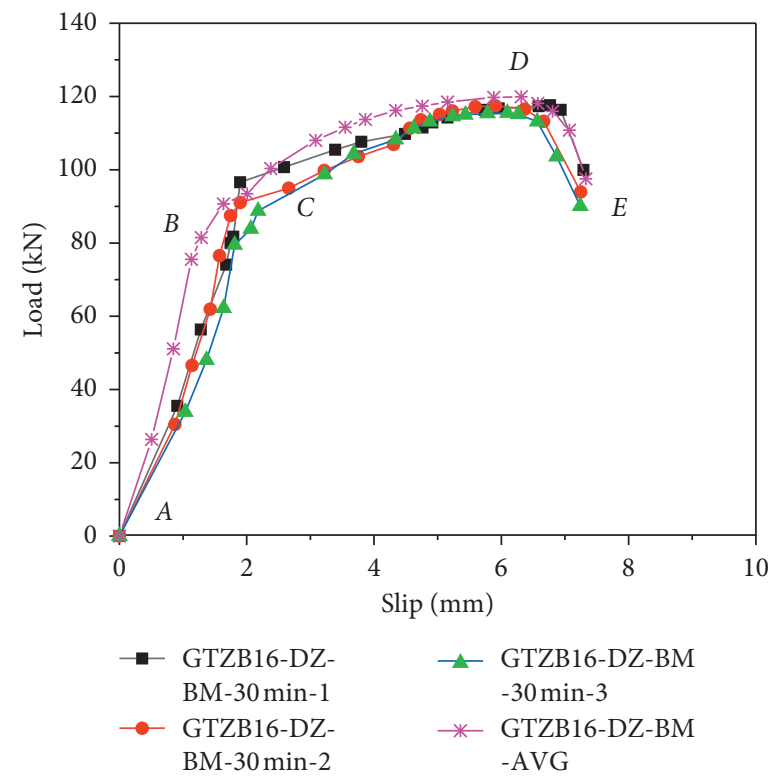

FIGURE 18: The load-slip curves of overtime grouting specimens (AVG: average value).

connecting rebar; that is, the standard value of tensile strength of HRB400 rebar is $540 \mathrm{MPa}$. The order of rebar stress of each group of joints is as follows: control group $>$ overtime grouting specimen (30 $\mathrm{min})$ $>$ insufficient rebar anchor length specimen $(7.5 \mathrm{~d})$ $>$ insufficient rebar anchor length specimen $(6.5 \mathrm{~d})>$ rebar offset specimen $>$ insufficient grout height specimen $(6.5 \mathrm{~d})>$ insufficient compactness specimen (20\%) $>$ insufficient rebar anchor length specimen $(5.5 \mathrm{~d})$. Thus, it can be seen that the anchorage depth of rebar is the biggest factor affecting the bearing capacity of joints, followed by compactness and grouting height. 
TABLE 9: Experiment data of overtime grouting specimens.

\begin{tabular}{|c|c|c|c|c|c|c|c|}
\hline Type & Specimen number & $\begin{array}{l}\text { Ultimate load } \\
(\mathrm{kN})\end{array}$ & $\begin{array}{l}\text { Rebar stress } \\
(\mathrm{MPa})\end{array}$ & $\begin{array}{c}\text { Lower yield } \\
(\mathrm{kN})\end{array}$ & $\begin{array}{l}\text { Yield strength } \\
(\mathrm{MPa})\end{array}$ & $\begin{array}{l}\text { Slip } \\
(\mathrm{mm})\end{array}$ & Destruction mode \\
\hline \multirow{3}{*}{$\mathrm{F}$} & $\begin{array}{c}\text { GTZB16-DZ-BM- } \\
30 \mathrm{~min}-1\end{array}$ & 117.62 & 585.17 & 84.76 & 421.69 & 7.29 & $\begin{array}{l}\text { Rebar tension } \\
\text { fracture }\end{array}$ \\
\hline & $\begin{array}{l}\text { GTZB16-DZ-BM- } \\
30 \mathrm{~min}-2\end{array}$ & 117.46 & 584.37 & 82.80 & 411.94 & 7.25 & $\begin{array}{l}\text { Rebar tension } \\
\text { fracture }\end{array}$ \\
\hline & $\begin{array}{l}\text { GTZB16-DZ-BM- } \\
30 \mathrm{~min}-3\end{array}$ & 115.38 & 574.03 & 81.27 & 404.33 & 7.24 & $\begin{array}{l}\text { Rebar tension } \\
\text { fracture }\end{array}$ \\
\hline AVG & $\begin{array}{c}\text { GTZB16-DZ-BM- } \\
\text { AVG }\end{array}$ & 119.73 & 595.67 & 87.35 & 434.59 & 7.32 & $\begin{array}{l}\text { Rebar tension } \\
\text { fracture }\end{array}$ \\
\hline
\end{tabular}

TABLE 10: Comparison between finite element analysis and experimental results.

\begin{tabular}{|c|c|c|c|c|c|c|}
\hline \multirow{2}{*}{ Number } & \multicolumn{2}{|c|}{ Ultimate load $(\mathrm{kN})$} & \multirow{2}{*}{$P_{u}^{\prime} / P_{u}$} & \multicolumn{2}{|c|}{ Yield load (kN) } & \multirow{2}{*}{$P_{y}^{\prime} / P}$, \\
\hline & $P_{u}^{\prime}$ & $P_{u}$ & & $P_{y}^{\prime}$ & $P_{y}$ & \\
\hline GTZB16-DZ-BM & 118.19 & 119.73 & 0.99 & 86.31 & 87.35 & 0.99 \\
\hline GTZB16-DZ-WM-104 mm & 114.17 & 115.16 & 0.99 & 85.94 & 85.60 & 1.00 \\
\hline GTZB16-DZ-WM-20\% & 111.90 & 112.31 & 1.00 & 89.97 & 82.53 & 1.09 \\
\hline GTZB16-PZ-BM & 116.76 & 114.77 & 1.02 & 82.49 & 84.99 & 0.97 \\
\hline GTZB16-DZ-120 mm-BM & 116.07 & 116.80 & 0.99 & 87.05 & 84.25 & 1.03 \\
\hline GTZB16-DZ-104 mm-BM & 112.28 & 115.09 & 0.98 & 83.69 & 81.93 & 1.02 \\
\hline GTZB16-DZ-88 mm-BM & 102.46 & 97.14 & 1.05 & 78.70 & 66.69 & 1.18 \\
\hline GTZB16-DZ-BM-30 min & - & 116.82 & - & - & 82.94 & - \\
\hline
\end{tabular}

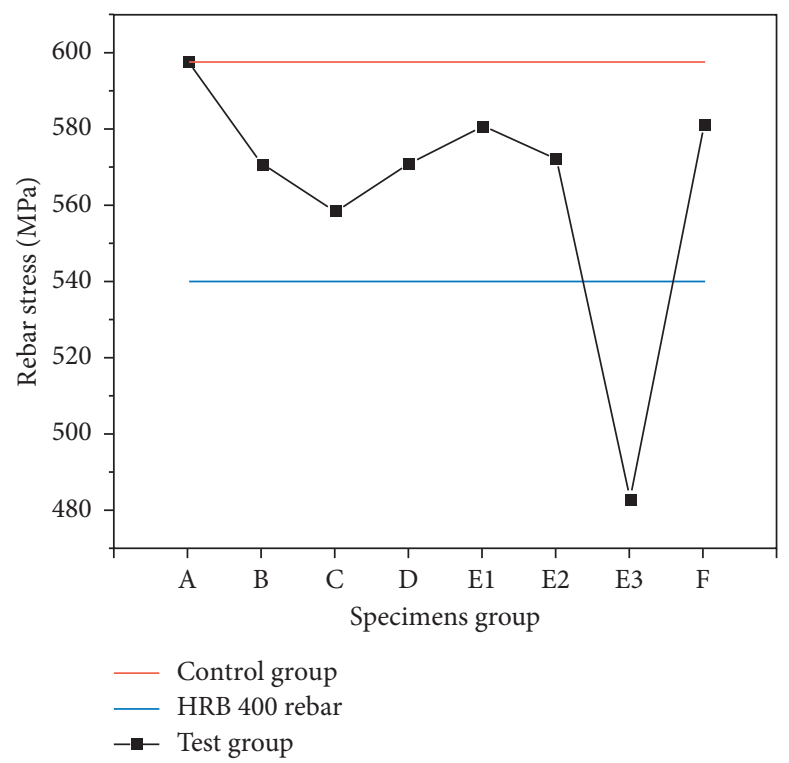

Figure 19: Comparison of rebar stress (unit: MPa). A, control group; B, insufficient grout height specimen; C, insufficient compactness specimen; D, rebar offset specimen; E, insufficient rebar anchor length specimen (E1: $7.5 \mathrm{~d}, \mathrm{E} 2: 6.5 \mathrm{~d}$, and E3: $5.5 \mathrm{~d}$ ); F, overtime grouting specimen.

\section{Conclusion}

The connection defects of sleeve connection between RC members can significantly increase the risk of the premature failure of PC infrastructures. To better understand the bond behavior of the sleeve connection, a systemic experimental investigation has been carried out on 24 specimens of sleeve connection subjected to tensile load. Based on the experimental observations and discussions, the main conclusions can be drawn as follows:

(1) The bearing capacity of joints falls, and the slip between sleeves and rebars decreases with the increment in different degrees of defects of grouting sleeves. The destruction mode is the rebar outside of joints fracture when the defect is less; the destruction mode changes, 
which leads to pullout failure of the lower part of the rebar with a little peel off of the grouting material as defects increase and surpass the critical value.

(2) The insufficient compactness is an important factor, affecting the bonding performance of sleeve connections. $20 \%$ of bubbles produced in the grouting material reduces the bond strength between the grouting material and sleeves and rebars, the anchoring force of the grouting material is not enough, the rebar does not meet the bearing capacity, the destruction mode is pullout of the lower part of the rebar, and the bearing capacity and the deformation capacity come down. In particular, the stress value of the joint and the rebar decreases, while the stress value of the grout and sleeve increases.

(3) The anchorage length of $5.5 \mathrm{~d}$ rebar is a very critical value. The uniaxial tension force of joints still meets the demand when the rebar anchoring length of sleeves is not less than $6.5 \mathrm{~d}$; the destruction of joints varies from rebar fracture to rebar pullout failure of the decline in bearing capacity and deformation capacity when the anchoring length is less than $5.5 \mathrm{~d}$. Due to the decrease in anchorage depth of rebar, the bond strength of grout can no longer meet the tensile strength.

(4) The destruction mode is the fracture of the upper part of the rebars, and the sleeve connection is still valid when the lower part of the rebar closely contacts the inner wall of sleeves which causes an increment in lateral stress on the upper part of the rebar.

(5) As for the GTZB4 16/16C joint, the vertical grouting height is $80 \% 8 \mathrm{~d}$, over 30 minutes grouting, and defects to rebar anchoring are $7.5 \mathrm{~d}$ and $6.5 \mathrm{~d}$, and the bearing capacity and deformation capacity of joints slightly descend, while the sleeve connection is still effective.

\section{Data Availability}

The data used to support the findings of this study are available from the corresponding author upon request.

\section{Conflicts of Interest}

The authors declare that they have no conflicts of interest.

\section{Acknowledgments}

The authors gratefully acknowledge the financial supports for this research by the Applied Basic Research Program of Shanxi Province under Grant no. 201801D221233 and Scientific and Technological Innovation Programs of Higher Education Institutions in Shanxi.

\section{References}

[1] W. Guo, Z. Zhai, Z. Yu, F. Chen, Y. Gong, and T. Tan, "Experimental and numerical analysis of the bolt connections in a low-rise precast wall panel structure system," Advances in Civil Engineering, vol. 2019, Article ID 7594132, 22 pages, 2019.
[2] JGT 398-2012, The Grouting Couple for Rebars Splicing, Ministry of Housing and Urban-Rural Development of China, Beijing, China, 2012.

[3] C.-G. Qin, G.-L. Bai, and Y.-Z. Xu, "Comparative study of seismic behavior between monolithic precast concrete structure and cast-in-place structure," Advances in Civil Engineering, vol. 2018, Article ID 7029287, 14 pages, 2018.

[4] D.-W. Zhang, "Service life prediction of precast concrete structures exposed to chloride environment," Advances in Civil Engineering, vol. 2019, Article ID 3216328, 14 pages, 2019.

[5] D.-Y. Wu, "Flexural capacity calculation approach for precast grouted shear wall influenced by joint interface displacements," Advances in Civil Engineering, vol. 2015, Article ID 120759, 11 pages, 2015.

[6] J.-W. Pan, X. Wang, and F. Wu, "Strengthening of precast RC frame to mitigate progressive collapse by externally bonded CFRP sheets anchored with HFRP anchors," Advances in Civil Engineering, vol. 2018, Article ID 8098342, 11 pages, 2018.

[7] W. Zhang, X. Deng, J. Zhang, and W. Yi, "Tensile behavior of half grouted sleeve connection at elevated temperatures," Construction and Building Materials, vol. 176, pp. 259-270, 2018.

[8] C. Zhao, Z. Zhang, J. Wang, and B. Wang, "Numerical and theoretical analysis on the mechanical properties of improved CP-GFRP splice sleeve," Thin-Walled Structures, vol. 137, pp. 487-501, 2019.

[9] F. Xu, K. Wang, S. Wang, W. Li, W. Liu, and D. Du, "Experimental bond behavior of deformed rebars in half-grouted sleeve connections with insufficient grouting defect," Construction and Building Materials, vol. 185, pp. 264-274, 2018.

[10] W. B. Lamport, J. O. Jirsa, and J. A. Yura, "Strength and behavior of grouted pile-to-sleeve connections," Journal of Structural Engineering, vol. 117, no. 8, pp. 2477-2498, 1991.

[11] A. Einea, T. Yamane, and M. K. Tadros, "Grout-filled pipe splices for precast concrete construction," PCI Journal, vol. 40, no. 1, pp. 82-93, 1995.

[12] D.-Y. Wu and S.-T. Liang, "Finite-element simulation on NPGCS precast shear wall spatial structure model," Advances in Civil Engineering, vol. 2019, Article ID 2647891, 17 pages, 2019.

[13] GBT 1499.2-2018, Steel for the Reinforcement of Concrete-Part 2: Hot Rolled Ribbed Bars, Standardization Administration of the People's Republic of China, Beijing, China, 2018.

[14] GB 50010-2010, Code for Design of Concrete Structures, Ministry of Housing and Urban-Rural Development of China, Beijing, China, 201.

[15] JGT 408-2013, Cementitious Grout for Couple of Rebars Splicing, Ministry of Housing and Urban-Rural Development of China, Beijing, China, 2013.

[16] H. Chen, "Finite element analysis of the grout sleeve splicing for rebars," Journal of Jiamusi University (Natural Science Edition), vol. 32, no. 3, pp. 341-344+349, 2014.

[17] Q.-L. Zheng, "Experimental Study on Effects of Grouted Defects on Behavior of Grout Sleeve Splicing and Specimens," China Academy of Building Research, Beijing, China, 2017.

[18] Y. Huang, Z. Zhenggeng, C. J. Naito, and Y. Weijian, "Tensile behavior of half grouted sleeve connections: experimental study and analytical modeling," Construction and Building Material, vol. 152, pp. 96-104, 2017. 